\title{
Who likes whom? The interaction between perceiver personality and target look
}

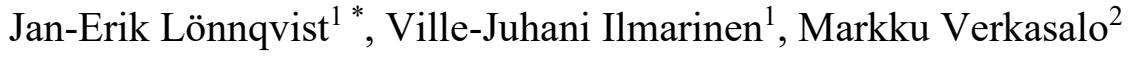 \\ Swedish School of Social Science, University of Helsinki, Finland \\ Swedish School of Social Science, University of Helsinki, Finland \\ Department of Psychology and Logopedics, University of Helsinki, Finland
}
* Correspondence to: Jan-Erik Lönnqvist, Swedish School of Social Science, University of Helsinki. Snellmaninkatu 12, PO Box 12, 00014 Helsinki, Finland. E-mail: jan- erik.lonnqvist@helsinki.fi

Acknowledgements: This research was supported by the Academy of Finland research grant 309537.

MV and J-EL designed the study. MV collected the data. J-EL and V-JI wrote the report. MV and VJI prepared the data. V-JI analysed the data.

Declaration of Interest: The authors have no competing interests.

\section{This is the submitted version of the manuscript that has been accepted for publication in Journal of Research in Personality.}

Citation:

Lönnqvist, J. E., Ilmarinen, V. J., \& Verkasalo, M. (2021). Who likes whom? The interaction between perceiver personality and target look. Journal of Research in Personality, 90.

https://doi.org/10.1016/j.jrp.2020.104044

Data and analysis script openly available at https://osf.io/ynvp2/ 
Abstract (118/120)

We investigated determinants of liking at zero-acquaintance, focusing on individual differences in perceivers' reactions to appearance cues. Perceivers $(N=385)$ viewed portrait photographs of Targets $(N=146)$. Perceiver's Agreeableness and Extraversion were uniquely associated with liking targets. Targets who expressed positive emotions, looked relaxed, were physically attractive, and looked healthy and energetic, were the most liked. There were substantial individual differences in how Perceivers were influenced by appearance cues. For instance, Perceivers generally rated targets who displayed non-Duchenne (fake) smiles less favorably than targets who did not smile or targets who displayed Duchenne (authentic) smiles. However, non-Duchenne smiles elicited especially negative ratings from Perceivers high in Neuroticism or Conscientiousness, but not from Perceivers low in Agreeableness.

Keywords: first impressions, zero-acquaintance, attractiveness, smiling, relationship effects 
Who likes whom? The interaction between perceiver personality and target look

As one of the founding fathers of modern social psychology, Solomon Asch (1948, p. 258), put it, 'We look at a person and immediately a certain impression of his character forms itself in us. A glance, a few spoken words are sufficient to tell us a story about a highly complex matter". Now, in an increasingly visual world (Hadlington, 2015), first impressions based on "a glance" will often determine whether two people ever meet up and exchange "a few spoken words" (e.g., Qiu \& Huang, 2020). The huge popularity of online social networks, recruitment tools, and dating services has made it highly likely that one will encounter pictures of a potential romantic partner, friend, or an employee when deciding whether to contact this person. Thus, photographs are today more important than ever, providing us with both a rich source of information about others, as well as a means to convey information about ourselves to others.

Although there exists some prior research on whom people generally like when rating pictures (e.g., relaxed and healthy looking targets), there is, to the best of our knowledge, no research on individual differences in these ratings. Some people may, e.g., like a more distinctive appearance than do others. Or, some may view fake smiles favorably, as signs of friendliness, whereas others may be more anxious, interpreting fake smiles as signs of deceitfulness and hidden intent. The present research investigates associations between the FFM personality traits and individual differences in whom and what we like when judging portrait photographs of strangers.

\section{Perceiver, target, and dyadic effects in ratings of likability}

Building on the Social Relations Model (SRM; Kenny, 1994) and the Realistic Accuracy Model (RAM; Funder,1999), Back et al. (2011) developed the Social Relations Lens Model (SRLM), which both distinguishes the different components of variance that are involved in interpersonal phenomena (as in SRM) and allows for investigating the processes that determine interpersonal perceptions (as in RAM). The following three variance components can be distinguished in SRLM:

(1) Perceiver variance refers to how much people generally differ in liking others; (2) Target variance refers to how the target persons differ in being liked; (3) Relationship variance refers to 
who likes whom; that is, how much is liking based on unique relational impressions with perceiver and target variance controlled for. Our research design fits into the SRLM framework with the exception that SRLM Relationship effects by definition refer to reciprocal ratings. Because our design is one-sided, we will denote the interaction effect between perceiver's personality and target's appearance a dyadic effect rather than a relationship effect.

The literature on perceiver effects shows that there exist stable individual differences in how positively perceivers generally rate others. Those with more desirable personality traits - low $\mathrm{N}$ and high $\mathrm{E}, \mathrm{OE}, \mathrm{A}$ and $\mathrm{C}$ - tend to rate targets more positively across all attributes, with the strongest effects for A (Wood et al., 2011).

Regarding target effects, we focused not on the psychological dispositions of the targets, but on how the targets looked in the photographs. That is, in the vocabulary employed by SRLM, we focused on cues observable in the portrait pictures, not the target's underlying psychological dispositions. These cues, which contained both static (related to physical grooming; e.g., style of dress) and dynamic (related to nonverbal expressive behavior; e.g. posture, facial expression) components, were mostly the same as those employed by Naumann et al. (2009), who, in a design rather similar to ours, had perceiver's rate target's personality traits based on portrait photographs. The appearance cues (how targets looked) were assessed by expert raters (different from the perceivers). Based on the results of Naumann et al., (2009), we expected looking healthy (as opposed to sickly), neat (vs. messy), energetic (vs. tired), relaxed (vs. tense) and smiling (vs. not smiling) to be associated with likability. Following Naumann et al. (2009), smiling was coded categorically. However, for a more fine-grained assessment of the expression of positive affect we added a continuous measure of laughing (vs. being tight lipped). Moreover, to capture the ambiguities of fashion (e.g., someone can put a lot of effort into signaling active dissent through clothing), we also included a measure that more directly assessed to what extent the target had prepared for the photo shoot. We expected both laughing and putting in some effort to positively predict liking. Moreover, the experts also assessed target on two items that were not so much objective appearance cues, but more like subjective personality perceptions. These two items were 
warmth (vs. competence) and femininity (vs. masculinity), both of which were included for purposes not directly relevant to this paper. However, for purposes of full disclosure, we included also these two items as appearance cues. Finally, because of a large body of literature suggesting that strangers rate attractive people more positively in almost every way (e.g., Dion et al., 1972; Eagly et al., 1991), we also added an assessment of physical attractiveness as an appearance cue.

Regarding dyadic effects between perceiver's personality and appearance cues, there is very little directly relevant empirical evidence to build on. A plausible reason for this gap in the literature could be that there is nothing to report on; people tend to agree on what is desirable and what is not, leaving little variance for perceiver's personality traits to explain. More or less everyone could be expected to favor, e.g., agreeable people over disagreeable people, leading to little variance in how favorably appearance cues signaling agreeableness are responded to. However, trait $\mathrm{O}$, and appearance cues signaling $\mathrm{O}$, could prove an exception. $\mathrm{O}$ is, at least in the present Finnish context, the only one of the five FFM personality factors that is ambiguous in terms of its desirability. Perhaps the most clear-cut evidence for this comes from a study (Lönnqvist et al., 2007) in which a sample of some 200 young adults responded first as applicants to a higher education institute (high pressure to respond desirably) and later as incumbents (low pressure to respond desirably). Mean scores on $\mathrm{E}, \mathrm{A}$, and $\mathrm{C}$ were much higher in the applicant condition than in the incumbent condition, whereas scores on $\mathrm{N}$ were much lower. Only $\mathrm{O}$ mean scores were nonresponsive to the applicant vs. incumbent context (Lönnqvist et al., 2007). These results suggest that there is no general consensus on which end of the $\mathrm{O}$ pole is more desirable, which in turn implies that there might be space for individual difference in how favorably perceivers respond to appearance cues signaling $\mathrm{O}$. Based on the well-established notion that perceived similarity breeds attraction (Montoya et al., 2008), we thus expected a dyadic effect between perceiver's $\mathrm{O}$ and appearance cues that could be thought to signal O; i.e., those higher in $\mathrm{O}$ were expected to favor targets who looked less traditional, more distinctive, and less well-prepared. 


\section{Duchenne and non-Duchenne smiles}

Naumann et al. (2009) employed smiling as a dichotomous yes/no variable. People who smile are generally perceived more positively. This effect was first reported by Thornton (1943) who found that smiling individuals tend to be rated higher in kindliness, honesty and sense of humor.

Numerous studies have found similar effects for other positive personality traits (Gunnery \& Ruben, 2016). However, Frank and Ekman (1993) famously argued that all smiles are not created equal, and showed that genuine smiles need to be distinguished from "fake smiles". Genuine smiles, often referred to as Duchenne smiles, include activation of the cheek raiser muscle that creates crow's feet around the eyes. These smiles are easily recognized by most observers as markers of positive mood. Non-Duchenne smiles, smiles without cheek raiser activation, refer to smiles that appear in the mouth but not the eyes and are recognized as non-genuine, often polite smiles (Duchenne de Boulogne, 1862; Ekman et al., 1990, 2002; Ekman \& Davidson, 1993; Frank et al., 1993; Manera et al., 2011).

Ekman and colleagues (Ekman 1992; Ekman, Davidson, and Friesen 1990; Ekman and Friesen 1982) showed that authentic smiles stimulate more positive emotional reactions by respondents than do "faked" smiles. A recent meta-analysis that compared perceptions of Duchenne smiles with perceptions of non-Duchenne smiles showed that more or less on any attribute, Duchenne smiles and the people producing Duchenne smiles are rated more positively (e.g., as more authentic, genuine, real, attractive, trustworthy) than non-Duchenne smiles and the people producing nonDuchenne smiles (Gunnery \& Ruben, 2016).

A Duchenne smile offers a clear signal of positive emotion (Ekman, 2007). By contrast, a nonDuchenne smile is ambiguous and obscures perception of positive or negative emotion (Prkachin and Silverman, 2002). When discerning the reason behind a non-Duchenne smile, it is necessary to consider the many possible functions of smiling (Niedenthal et al., 2010): People smile not only when they are happy and because a situation is benign, but also when trying to hide embarrassment (Kraut and Johnston, 1979), uncertainty (Labarre, 1947), or sadness (Klineberg, 1940), as well as when they seek power in their communication (Hecht and LaFrance, 1998). In 
addition, a nonDuchenne smile can also signal politeness. People can use a polite smile to mask negative emotions (Ekman et al., 1988; Morse and Afifi, 2015), to meet social demands (Ekman and Friesen, 1982), or to communicate appeasement (Papa and Bonanno, 2008). They are often interpreted positively, as signaling willingness to be approached (Niedenthal et al., 2010), to be polite, and to meet social demands (Ekman and Friesen, 1982; Morse and Afifi, 2015). However, they can also be displayed in order to hide negative emotions (Kraut and Johnston, 1979; Klineberg, 1940; Labarre, 1947) and can even be viewed as deceitful (Delmas et al., 2019).

There is very little if any research on how different smiles are perceived by different people. In the more general literature on the associations between personality and the processing of social information, much of the literature has focused on N. The results of this research have demonstrated the central role of $\mathrm{N}$ in determining reactions to a variety of threatening situations, with those scoring high on N reacting more anxiously to both threatening (Gross, Sutton, \& Ketelaar, 1998; Larsen \& Ketelaar, 1989; Norris, Larsen, \& Cacioppo, 2007) and neutral cues (Lundh \& Öst, 1996; Yoon \& Zinbarg, 2008). Participants scoring high on N could thus be expected to react anxiously to non-Duchenne smiles, being more likely to perceive it as a deceitful mask than as signaling friendliness. The other trait that could be expected to be relevant in the perception of non-Duchenne smiles is A. Disagreeable individuals, although correctly perceiving interpersonal perceptual cues, may not be motivated to attend to the mental states underlying these cues (Nettle \& Liddle, 2008). This implies that disagreeable individuals may take a smile at face value, as a friendly gesture, without penalizing for insincerity.

\section{The present research}

The purpose of the present research was to investigate determinants of liking at zero-acquaintance. Rating of liking were based on portrait photographs in which the target was framed from knees up. We extend upon previous work by focusing not only on perceiver and target effects, but also on the possible dyadic effects between perceiver personality and target's appearance. I.e., we investigate whether there are individual differences in how perceiver's respond to specific cues. The other novel contribution of the present research comes from our focus on smiling. In particular, we are 
interested in how people perceive fake smiles. Is fake smiling generally viewed more favorably or unfavorably than not smiling at all? Do some see fake smiles as signs of a friendliness, reacting favorably, whereas others see them as a signs of deceit, reacting unfavorably? The study was not preregistered.

\section{Method}

\section{Participants and procedure}

Perceivers were 385 undergraduates $(87.5 \%$ female; mean age $=25.41(\mathrm{SD}=6.63))$ who completed a five-factor personality inventory and provided liking ratings for 146 targets $(51.4 \%$ female; mean age $=34.00, \mathrm{SD}=4.14$ ). Each perceiver rated one of fifteen sets of portraits (each set consisted of between 7 and 33 target portraits; $M=13.09, S D=8.08$; the amount varied as a function of how much compensatory course credit perceivers received). Each target portrait was included on average in 2.98 sets $(S D=1.12$; range from 1 to 5$)$, which amounted to each portrait being rated by between 28 and 40 perceivers $(M=34.51, S D=3.22)$. The total number of liking ratings was 5039 . Targets' appearance was rated by two independent sets of raters; 11 trained expert raters provided ratings of 102 targets, and 9 more expert raters provided ratings of the remaining 44 targets. Two additional independent sets of raters $(\mathrm{m}=11$ and $\mathrm{m}=7$, for the 102 and 44 targets, respectively) provided assessment on targets' physical attractiveness. The reason we had the targets divided into samples of 102 and 44 were practical (parental leaves, time constraints). The 146 targets (50\% women; the mean age of female targets was 32 years $(\mathrm{SD}=3.87$; range: $21-44)$, and the mean age of male targets was 34 years $(\mathrm{SD}=5.03$; range $=23-52$ years $)$ had taken part in an unrelated previous study (masked for review) and were offered a professional-level portrait (worth around $100 €$ ) as an incentive to participate. The number of targets was determined by how many of the 292 participants who took part in the previous study volunteered (everyone was invited). The number of perceivers was determined by the number of undergraduates enrolled in two different introductory classes.

\section{Statistical power}

Given the sample sizes, with .80 statistical power and type I error set at .05 , we had sensitivity to detect perceiver and target effects of magnitudes $r=.14$ and $r=.23$, respectively. Based on sample 
sizes (we used a slightly simplified two-level simulation scenario with 385 perceivers who each provided liking ratings of 13 different targets), random slope variation (set at .10 in SD-metric), and the magnitude of the cross-level interaction (set at .05; see Mathieu et al., 2012), the power to detect a cross-level interaction effect was .92. See osf.io/ynvp2/ for the power analysis scripts.

\section{Measures}

Liking. Liking was assessed by the item "To what extent do you think you would like this person?", which was responded to on a 11-point scale ranging from 0 (not at all) to 10 (very much; $M=5.41, S D=1.07)$.

Perceiver personality. Personality was measured with the Finnish language version of the 30 -item eXtra Short Five (XS5; Konstabel et al., 2017) personality questionnaire, which was created to mimic the NEO PI-R — probably the most widespread and extensively validated measure of the traits identified by the FFM (Costa and McCrae, 1992). Trait-wise correspondence between the XS5 and the NEO PI-R measures ranges from $r=.77$ (agreeableness) to $r=.89$ (neuroticism; Konstabel et al., 2017). The internal consistency reliabilities of the XS5 were .77, .75, .58, .59 and .67, for ratings of N, E, O, A and C, respectively. Descriptive statistics and inter-correlations between perceiver variables are presented in Table S1 in the Supplementary Online Material (SOM).

Physical appearance cues. The targets portrayed in portrait photographs (knee up; see Figures S1 and S2 in SOM) were rated on eleven characteristics related to physical appearance (provided by 11 and 9 expert raters, for 102 and 44 targets, respectively). The bipolar 7-point scales, anchored by opposite adjectives, were sickly-healthy, not at all prepared-very prepared (for the photoshoot), non-traditional-traditional, unstylish-stylish, distinctive-ordinary, messy-neat, tight-lippedlaughing, tired-energetic, tense-relaxed, cold-warm, and masculine-feminine (the first nine were from a similar study by Naumann et al., 2009). Descriptive statistics, interrater agreement, and intercorrelations between physical appearance cues are presented in Table S2. Interrater agreement ranged between .70 and .90 across all ratings and sets of targets.

Smiling. The same experts who rated appearance were also requested to categorize the target's facial expression by making a forced choice between three options: Duchenne (authentic smile), 
Non-Duchenne (fake smile), or no-smile. The proportion of experts who chose each option indicated the extent to which a given target's smile was perceived as authentic, fake, or absent. Interrater agreement, calculated by Fleiss' kappa, was very low for Duchenne smile (.14/.18), for the separate sets of 102 and 44 targets) and for no-smile (.27/.34), but clearly higher for NonDuchenne smiling (.58/.67). The low interrater agreement for Duchenne smile and no-smile was unexpected. Numerous studies have shown that the average person readily can distinguish authentic from fake smiles when reading others' facial expressions (e.g., Mehu et al., 2007). In light of the low agreement for Duchenne smile and no-smile, we will not elaborate on any results that involve them (although we will present them in the tables).

Physical attractiveness. Raters sorted female and male targets separately to 10 piles of roughly equal size (i.e. 5 for first set of targets and 2 for second set) based on their physical attractiveness following which values from 1 to 10 from the least physically attractive to the most physically attractive were assigned for each target. Interrater agreement for physical attractiveness was .89 and .86 , in the first and second set of targets, respectively.

\section{Statistical analysis}

The design of our social relations data (each perceiver rated a certain set of targets and almost all targets were included in multiple sets) corresponded to an asymmetric half-block design (Malloy, 2018). We therefore employed cross-classified multilevel modeling, in which each liking rating (standardized prior to analysis) was assigned to a specific target and a specific perceiver, allowing us to compute the proportion of variance attributable to target and perceiver effects. The baseline model for ratings of liking is presented in Equation 1.

$$
\text { Liking }_{i j k}=\beta_{0}+u_{j}+v_{k}+e_{i j k}
$$

The liking ratings for a perceiver-target dyad $i$, were modeled as a function of the overall mean of liking ratings $\left(\beta_{0}\right)$, perceiver $j$ 's mean liking ratings $\left(\mathrm{u}_{\mathrm{j}}\right)$, target $k$ 's mean liking ratings $\left(\mathrm{v}_{\mathrm{k}}\right)$, and the residual error term $\left(\mathrm{e}_{\mathrm{ijk}}\right)$. 
In each of the following steps, models included as covariates the sex (coded -0.5 for females, 0.5 for males) and the age of the perceiver and of the target, as well as a variable that indicated whether it was a same-sex or different-sex dyad. The association between perceiver's personality and liking was examined by adding standardized personality trait scores (one at a time) into the model. The association between target appearance and liking was examined by including appearance cues (one at a time; including smiling) into the model. The appearance cues were first standardized and then grand mean centered across targets, equating all intercepts to the same location. After examining the main effects of appearance cues, we tested for existence of individual differences in who likes which cues. I.e., the random slope by perceiver was added to a model that included the fixed effect of the appearance cue. The random slope model is presented in Equation 2.

$$
\begin{aligned}
& \text { Liking }_{i j k}=\beta_{0}+\beta_{1} \operatorname{sex}_{j}+\beta_{2 \operatorname{sex}_{k}}+\beta_{3}\left(\operatorname{sex}_{j} \times \operatorname{sex}_{k}\right)+\beta_{4} \text { age }_{j}+\beta_{5} \text { age }_{k} \\
& +\left(\beta_{7}+u_{1 j}\right) \text { Appearance cue } \\
& k
\end{aligned}
$$

The fixed effect of appearance cues on ratings of liking of targets $(k)$ was given by $\beta_{7}$ and the random effect of how appearance cues were associated with ratings by certain perceivers $j$ was given by $u_{1 j}$.

In case there was variation (tested by a likelihood ratio tests) across perceivers we examined whether this variation was associated with perceiver's personality traits. The interaction term between each appearance cue and each personality trait was, one at a time, added to the model, and the statistical significance of the interaction term was tested (Satterthwaite's approximation for degrees of freedom was employed for this). The cross-level interaction model is presented in Equation 3.

$$
\begin{aligned}
& \text { Liking }_{i j k}=\beta_{0}+\beta_{1 \text { sex }_{j}}+\beta_{2 \text { sex }_{k}}+\beta_{3}\left(\text { sex }_{j} \times \text { sex }_{k}\right)+\beta_{4} \text { age }_{j}+\beta_{5} \text { age }_{k}+\beta_{6} \text { Personality }_{j} \\
& +\left(\beta_{7}+u_{1 j}\right) \text { Appearance cue } k+\beta_{8}\left(\text { Personality }_{j} \times \text { Appearance cue }_{k}\right)+u_{j} \\
& +v_{k}+e_{i j k}
\end{aligned}
$$

Because of the potentially large number of significant cross-level interactions, we required that the interaction was significant both when added alone (e.g., $\mathrm{E} \times$ stylish) and when added together with 
other traits' cross-level interactions with the same appearance cue (e.g., E x Stylish, A x Stylish, OE x Stylish, C x Stylish, N x Stylish). The effect size was estimated by the variance accounted for (pseudo-R2), computed from the reduction of variance in liking ratings (between-target variance for target effects, between-perceiver variance for perceiver effects, and random slope variance for cross-level interactions). Although this approach comes with certain problems (it can, e.g., because of the inherent complexity in multi-level models produce negative values of variance accounted for; LaHuis et al., 2014; Rights \& Sterba, 2019), we considered it adequate in the context of the present cross-classified data structure.

All analysis were run in R (R Core Team, 2019). The lmer -package (Bates et al., 2015) was used for multilevel modeling. Analysis script and data for reproducing the results are available at osf.io/ynvp2/.

\section{Results}

\section{Variance components and covariates}

In the intercept only model, $21.46 \%$ and $18.10 \%$ of the total variance in liking ratings was between perceivers and targets, respectively. In the model with covariates, female perceivers liked more $(b=$ $-0.23, p=.005)$ and female targets were liked more $(b=-0.33, p<.001)$. Neither age nor combination of sexes in the perceiver-target dyad were associated with liking. Of the remaining total variance, $21.67 \%$ and $15.68 \%$ were between perceivers and targets, respectively. See Table 1 for these models.

\section{Perceiver effects: Who likes the targets?}

The associations between perceivers' personality traits and liking ratings are shown in Table S3 (the full model tables are in Table S4). Although E, OE, A, and low N were all associated with higher average liking ratings, only $\mathrm{A}$ and $\mathrm{E}$ showed unique associations with liking when other traits were controlled for.

\section{Target effects: Which appearance cues are liked, and does this vary?}


For each appearance cue, after fixed effects, we entered random effect by perceiver to estimate possible individual differences in who likes which cues. We also estimated the covariation between perceiver random effects (whether individual differences in who likes which appearance cues are associated with perceiver's average liking), but they were never statistically significant (for all, $p>$ .289), and were excluded from subsequent analysis. Fixed and random effects for appearance cues are presented in Table 2.

Except for unprepared-prepared, non-traditional-traditional, distinctive-ordinary, and messy-neat, all appearance cues were associated with being liked. Being rated as healthy, stylish, laughing, energetic, relaxed, warm, feminine, attractive was associated with being more liked (we mention the results for warmth and femininity, but will not discuss them further). Non-Duchenne smiling was negatively associated with being liked. In addition, except for unstylish-stylish $(p=.182)$ and messy-neat $(p=.112)$, the associations between appearance cues and liking varied between perceivers (as indicated by the random slope estimates, all $p<.007$ ). Perceivers' ratings of liking were thus not similarly influenced by most appearance cues.

For a higher-level lens-model summary of our results, we examined the total variance accounted for by all appearance cues and by personality. The random intercept variance parameter estimates are presented in Table S5. Together the appearance cues accounted for half $(50.78 \%)$ of the variance between targets. Of the remaining total variance, $6.79 \%$ was between targets and $24.61 \%$ between perceivers. When all five perceiver personality traits were included in the model, they accounted for a total $10.16 \%$ of the between perceiver variance in liking ratings. When all of these fixed effects were included, $22.21 \%$ of the total variance was between targets and $7.01 \%$ was between perceivers.

\section{Is personality associated with liking certain cues?}

As noted above perceivers' ratings of liking were not similarly influenced by most appearance cues. We examined these cues' cross-level interactions with perceiver's personality traits. A summary of the associations is presented in Table 3, and the model parameter estimates are presented in Tables S6-S18. 
We expected those high in $\mathrm{O}$ to favor targets who appeared more similar to themselves. Consistent with this, distinctive and non-traditional looking targets, although not generally more liked, were rated more favorably by those high in $\mathrm{O}$, as well as were targets who looked less well prepared for the photo shoot. Interestingly, physical attractiveness made less of a positive impression on perceivers high in $\mathrm{O}$. As expected, those high in $\mathrm{N}$ viewed non-Duchenne smiles even more unfavorably than did others. Also as expected, those low in A viewed them more favorably than did others.

Not only the expected interactions were statistically significant. Extraverts favored, even more than others, those who looked healthy, well-prepared, traditional, and physically attractive. Similar to the above results for $\mathrm{O}$, those high in $\mathrm{A}$ also liked targets who looked more distinctive and nontraditional, as well as targets who appeared feminine. Those high in $\mathrm{C}$ also liked more feminine targets more, as well as favoring energetic looking targets. Finally those high in C, like those high in $\mathrm{N}$, viewed non-Duchenne smiles unfavorably.

\section{Discussion}

Regarding perceiver effects, the results echo those of previous research. Perceivers high in A clearly liked targets more, with E also uniquely contributing to high liking. Also regarding target effects, the results were very similar to those reported on by Naumann et al. (2009). Targets who were laughing and relaxed were clearly the most liked. Looking energetic and healthy was also associated with being liked, as well as being physically attractive. Also targets rated as stylish were more liked. Regarding smiles, a novel result of the present research was that both neutral faces and those displaying Duchenne smiles were received more favorably than those displaying nonDuchenne smiles. We expected the most important and novel contributions of the present research to pertain to the dyadic effects between perceiver personality and target appearance. Indeed, there were individual differences in how favorably people reacted to the appearance cues for almost all cues.

\section{Who likes what?}


We expected appearance cues signaling openness to be received positively (negatively) by perceivers high (low) in $\mathrm{O}$. Indeed, perceiver openness was positively associated with liking targets who looked non-traditional, distinctive, and less well prepared. Open perceivers also gave less weight to attractiveness. Our results are consistent with other results suggesting that $\mathrm{O}$ differs from the other traits in being less normatively evaluative; those high in $\mathrm{O}$ will like others high in $\mathrm{O}$, whereas the opposite pattern holds for those low in O. Besides being received unfavorably by those high in $\mathrm{O}$, a traditional or ordinary appearance was also responded to negatively by those high in A. This could, at least in part, be due to those high in A being generally less prejudiced towards others (Sibley \& Duckitt, 2008), also people who look different from the norm.

Those who looked healthy, prepared, traditional, or attractive were, although generally liked by everyone, even more liked by extraverts than by introverts. One reason for this could be that extraverts themselves care more about how they look; extraverts tend to wear more stylish and expensive cloths, be better groomed, and generally look better (Meier et al., 2010; Vazire et al., 2008). One could imagine that extraverts, seeing someone similar to themselves, could judge the person more favorably. The same explanation, in which perceived similarity breeds attraction (Montoya et al., 2008), could be the reason for why those high in C favored targets who were well prepared and had a more energetic appearance. As expected, more neurotic individuals disliked non-Duchenne smiles. Also as expected, those low in A did not dislike non-Duchenne smiles as much as others did. Not expected was that those high in $\mathrm{C}$ disliked these smiles especially much. These effects will be discussed below.

\section{Should one smile in portrait photographs?}

People who smile are generally perceived more positively (Thornton, 1943; Gunnery \& Ruben, 2016). However, smiling has not always been the norm in portrait photographs. In the late $19^{\text {th }}$ century people posing for photographs still followed the habits of painted portraiture subjects, which meant keeping a serious expression, in part because a smile was difficult to maintain, in part because of beauty standards that included a small mouth (Kotchemidova, 2005). All of this changed with the advent of amateur photography in the beginning of the 20th century. This set into motion a 
rapid increase in the popularity and intensity of smiles in portraiture, a trend that still continues today (Ginosar et al., 2015; Kotchemidova, 2005).

Consistent with the present normativity of smiling in photographs, Duchenne smiles were received favorably. A much more novel results was that non-Duchenne smiles were viewed negatively. Previous research has not explicitly compared non-Duchenne smiles to neutral expressions (Gunnery \& Ruben, 2016). Given that those high in N were, as expected, particularly negative towards these smiles, one explanation for the unfavorable impression made by non-Duchenne smiles could be that they are perceived as threatening. They could mask deceit or hidden intent, something those high in $\mathrm{N}$ could be particularly like to respond to (e.g., Gross et al., Norris et al., 2007; Yoon \& Zinbarg, 2008). Also as expected, those low in A, less motivated to scrutinize the intent of others (Nettle \& Liddle, 2008), did not penalize non-Duchenne smiles for lack of sincerity. Unexpectedly, those high in $\mathrm{C}$ rated targets displaying non-Duchenne smiles more negatively. This was an unexpected but intriguing finding. Those high in $\mathrm{C}$ may see non-Duchenne smiles not so much as a signs of threat, but as superfluous and unnecessary - seriousness of intent is often thought to be one of the defining features of $\mathrm{C}$. Those high in $\mathrm{C}$ could have been more comfortable with the norms of the late $19^{\text {th }}$ century, when people posing for photographs were expected to keep a serious expression.

An intriguing question is to what extent the results pertaining to non-Duchenne smiles are culture specific. Although Finland, and European countries in general, tend to receive high scores on largescale cross-cultural happiness surveys, such as the World Happiness Survey (Helliwell et al., 2019), people in these countries smile less than people on any other continent, at least as judged from their social media content (Kang et al., 2019). It could be that in cultures in which smiling is more normative, also non-Duchenne smiles would be viewed more positively. More generally, there may be severe limitations to the generalizability of our findings, especially given that beauty standards may change culturally and be specific to certain historical contexts, of which smiling itself in an excellent example. 
One conclusion of the present research is that one should not attempt to fake a smile for photographs unless one can pull of a Duchenne smile. Some people can do this, but others cannot (Gunnery, et al., 2013). Another conclusion is that relationship effects should be given more attention in research on interpersonal perception. Until now, little has been done to understand or explain these effects. Our results, suggesting that many of the FFM personality traits are relevant for determining how we respond to specific cues, are a first step in that direction. 


\section{References}

Asch, S. E. (1948). The doctrine of suggestion, prestige, and imitation in social psychology. Psychological Review, 55, 250-276.

Back M. D., Stopfer J. M., Vazire S., Gaddis S., Schmukle S. C., Egloff B., Gosling S. D. (2010). Facebook profiles reflect actual personality not self-idealization. Psychological Science, 21, 372374.

Bates, D., Mächler, M., Bolker, B., \& Walker, S. (2015). Fitting Linear Mixed-Effects Models Using lme4. Journal of Statistical Software, 67(1), 1-48.

Cuperman, R., \& Ickes, W. (2009). Big Five predictors of behavior and perceptions in initial dyadic interactions: Personality similarity helps extraverts and introverts, but hurts "disagreeables". Journal of personality and social psychology, 97(4), 667-684.

Dion, K., Berscheid, E., \& Walster, E. (1972). What is beautiful is good. Journal of Personality and Social Psychology, 24, 285-290.

Eagly, A. H., Ashmore, R. D., Makhijani, M. G., \& Longo, L. C. (1991). What is beautiful is good, but. . .: A metaanalytic review of research on the physical attractiveness stereotype. Psychological Bulletin, 110, 109-128.

Ginosar, S., Rakelly, K., Sachs, S., Yin, B., \& Efros, A. A. (2015). A century of portraits: A visual historical record of american high school yearbooks. In Proceedings of the IEEE International Conference on Computer Vision Workshops (pp. 1-7).

Gunnery, S. D., Hall, J. A., \& Ruben, M. A. (2013). The deliberate Duchenne smile: Individual differences in expressive control. Journal of Nonverbal Behavior, 37(1), 29-41.

Hadlington, L. (2015). Cognitive factors in online behaviour. In A. Attrill (Ed.), Cyberpsychology (pp. 249-267). Oxford, England: Oxford University Press.

Helliwell, J., Layard, R., \& Sachs, J. (2019). World Happiness Report 2019, New York: Sustainable Development Solutions Network. 
Kang, Y., Jia, Q., Gao, S., Zeng, X., Wang, Y., Angsuesser, S., ... Fei, T. (2019). Extracting human emotions at different places based on facial expressions and spatial clustering analysis. Transactions in GIS, 23, 450-480.

Konstabel, K., Lönnqvist, J.-E., Leikas, S., García Velázquez, R., Qin, H., Verkasalo, M., \& Walkowitz, G. (2017). Measuring single constructs by single items: Constructing an even shorter version of the "Short Five" personality inventory. PLOS ONE, 12(8), e0182714.

Kotchemidova, C. (2005). Why we say "cheese": Producing the smile in snapshot photography. Critical Communication, 22, 2-25.

LaHuis, D. M., Hartman, M. J., Hakoyama, S., \& Clark, P. C. (2014). Explained Variance Measures for Multilevel Models. Organizational Research Methods, 17(4), 433-451.

https://doi.org/10.1177/1094428114541701

Lönnqvist, J. E., Paunonen, S., Tuulio_ Henriksson, A., Lönnqvist, J., \& Verkasalo, M. (2007). Substance and style in socially desirable responding. Journal of Personality, 75(2), 291-322.

Lundh, L. G., \& Öst, L. G. (1996). Face recognition in patients with social phobia. Scandinavian Journal of Behaviour Therapy, 25, 139-148.

Malloy, T. E. (2018). Social Relations Modeling of Behavior in Dyads and Groups. Elsevier. https://doi.org/10.1016/C2016-0-02324-0

Mathieu, J. E., Aguinis, H., Culpepper, S. A., \& Chen, G. (2012). Understanding and estimating the power to detect cross-level interaction effects in multilevel modeling. Journal of Applied Psychology, 97(5), 951-966. https://doi.org/10.1037/a0028380

Mehu, M., Little, A. C., \& Dunbar, R. I. (2007). Duchenne smiles and the perception of generosity and sociability in faces. Journal of Evolutionary Psychology, 5, 183-196.

Meier, B. P., Robinson, M. D., Carter, M. S., \& Hinsz, V. B. (2010). Are sociable people more beautiful? A zero-acquaintance analysis of agreeableness, extraversion, and attractiveness. Journal of Research in Personality, 44, 293-296. 
Montoya, R. M., Horton, R. S., \& Kirchner, J. (2008). Is actual similarity necessary for attraction? A meta-analysis of actual and perceived similarity. Journal of Social and Personal Relationships, 25(6), 889-922.

Naumann L. P., Vazire S., Rentfrow P. J., Gosling S. D. (2009). Personality judgments based on physical appearance. Personality and Social Psychology Bulletin, 35, 1661-1671.

Nettle, D., \& Liddle, B. (2008). Agreeableness is related to social_ cognitive, but not social _ perceptual, theory of mind. European Journal of Personality, 22, 323-335.

Qiu, H., \& Huang, S. (2020). Mobile Dating, Relational Communication, and Motivations for AIDS Risk Reduction among Chinese MSM College Students. Health Communication, 35(3), 289-296.

R Core Team. (2019). R: A language and environment for statistical computing. https://www.Rproject.org/

Rights, J. D., \& Sterba, S. K. (2019). Quantifying explained variance in multilevel models: An integrative framework for defining R-squared measures. Psychological Methods, 24(3), 309-338.

Schwartz, S. H., Verkasalo, M., Antonovsky, A., \& Sagiv, L. (1997). Value priorities and social desirability: Much substance, some style. British journal of social psychology, 36, 3-18.

Sibley, C. G., \& Duckitt, J. (2008). Personality and prejudice: A meta-analysis and theoretical review. Personality and Social Psychology Review, 12(3), 248-279.

Thornton, G. R. (1943). The effect upon judgments of personality traits of varying a single factor in a photograph. Journal of Social Psychology, 18, 127-148.

Vazire, S., Naumann, L. P., Rentfrow, P. J., \& Gosling, S. D. (2008). Portrait of a narcissist: Manifestations of narcissism in physical appearance. Journal of Research in Personality, 42(6), 1439-1447.

Wach, M., \& Hammer, B. (2003) La structure des valeurs est-elle universelle? In M. Huteau (Ed.), Genèse et validation du modèle compréhensif de Schwartz. Paris: L'Harmattan.

Wallace, E. (1913). Mark Twain and the happy island. Chicago: A.C. McClurg \& Co. 
Yoon, K. L., \& Zinbarg, R. E. (2008). Interpreting neutral faces as threatening is a default mode for socially anxious individuals. Journal of abnormal psychology, 117(3), 680-685. 
Table 1

Parameter estimates from null and covariate models for liking ratings where liking ratings varied between targets and perceivers

\begin{tabular}{lcccc}
\hline Fixed effects & Est. & $p$ & Est. & $p$ \\
\hline Intercept $\left(\beta_{0}\right)$ & -0.00 & .936 & -0.09 & .076 \\
Perceiver sex $\left(\beta_{1}\right)$ & & & -0.23 & .005 \\
Target sex $\left(\beta_{2}\right)$ & & & -0.33 & $<.001$ \\
Perceiver sex $\times$ Target sex $\left(\beta_{3}\right)$ & & -0.09 & .191 \\
Perceiver age $\left(\beta_{4}\right)$ & & 0.00 & .605 \\
Target age $\left(\beta_{5}\right)$ & & -0.01 & .116 \\
Random Effects & & & \\
Residual $\left(\mathrm{e}_{\mathrm{ijk}}\right)$ & 0.61 & \multicolumn{2}{c}{0.61} & \\
Intercept by perceiver $\left(\mathrm{u}_{\mathrm{j}}\right)$ & 0.22 & \multicolumn{2}{c}{0.21} & \\
Intercept by target $\left(\mathrm{v}_{\mathrm{k}}\right)$ & 0.18 & \multicolumn{2}{c}{0.15} & \\
\hline
\end{tabular}

Note. .tar and .per refer to target- and perceiver-level variables, respectively. Sex coded -0.5 for females, 0.5 for males. Random effects in variance metric. 
Table 2

Fixed and random effects for target appearance cues in associations with interpersonal liking

\begin{tabular}{lccccccc}
\hline & \multicolumn{3}{c}{ Fixed effect $\left(\beta_{7}\right)$} & & \multicolumn{2}{c}{$\begin{array}{c}\text { Random effect } \\
\text { (standard deviation } \\
\left.\text { of } \mathrm{u}_{1 \mathrm{j}}\right)\end{array}$} \\
\cline { 2 - 3 } \cline { 7 - 8 } Appearance & $\mathrm{b}$ & $p$ & $\mathrm{R}^{2}$ & & Est. & $p$ \\
\hline Sickly-Healthy & 0.15 & $<.001$ & .12 & & 0.10 & .005 \\
Unprepared-Prepared & 0.02 & .646 & .00 & & 0.13 & $<.001$ \\
Non-traditional-Traditional & -0.01 & .872 & .00 & & 0.11 & .001 \\
Unstylish-Stylish & 0.08 & .017 & .04 & & 0.07 & .182 \\
Distinctive-Ordinary & -0.01 & .801 & .00 & & 0.10 & .002 \\
Messy-Neat & 0.03 & .318 & .01 & & 0.08 & .112 \\
Tight-lipped-Laughing & 0.25 & $<.001$ & .35 & & 0.15 & $<.001$ \\
Tired-Energetic & 0.19 & $<.001$ & .20 & & 0.13 & $<.001$ \\
Tense-Relaxed & 0.24 & $<.001$ & .32 & & 0.13 & $<.001$ \\
Cold-Warm & 0.27 & $<.001$ & .38 & & 0.15 & $<.001$ \\
Masculine-Feminine & 0.24 & $<.001$ & .08 & & 0.15 & $<.001$ \\
Attractiveness & 0.19 & $<.001$ & .18 & & 0.10 & .006 \\
Non-Duchenne smile & -0.26 & $<.001$ & .33 & & 0.14 & $<.001$ \\
Duchenne smile & 0.17 & $<.001$ & .14 & & 0.10 & .001 \\
No smile & 0.24 & $<.001$ & .29 & & 0.12 & $<.001$ \\
\hline
\end{tabular}

Note. $\mathrm{R}^{2}=$ Pseudo $\mathrm{R}^{2}$-metric calculated from variance accounted between targets. Random effect significance tested with likelihood-ratio test between models where the random effect was included or excluded. 
Table 3

Target appearance $\times$ Perceiver personality cross-level interaction estimates in associations with interpersonal liking

\begin{tabular}{|c|c|c|c|c|c|c|c|c|c|c|c|c|c|c|c|}
\hline & \multicolumn{3}{|c|}{ Neuroticism } & \multicolumn{3}{|c|}{ Extraversion } & \multicolumn{3}{|c|}{ Openness } & \multicolumn{3}{|c|}{ Agreeableness } & \multicolumn{3}{|c|}{ Conscientiousness } \\
\hline & Est. & $p$ & $\mathrm{R}^{2}$ & Est. & $p$ & $\mathrm{R}^{2}$ & Est. & $p$ & $\mathrm{R}^{2}$ & Est. & $p$ & $\mathrm{R}^{2}$ & Est. & $p$ & $\mathrm{R}^{2}$ \\
\hline Sickly-Healthy & 0.01 & .450 & .02 & 0.04 & .002 & .10 & -0.02 & .127 & .05 & -0.01 & .512 & .00 & 0.02 & .080 & .04 \\
\hline Unprepared-Prepared & -0.01 & .571 & .00 & 0.03 & .031 & .06 & -0.03 & .026 & .04 & -0.01 & .519 & -.01 & 0.04 & .003 & .09 \\
\hline Non-traditional-Traditional & -0.03 & .034 & .12 & 0.03 & .032 & .08 & -0.05 & .001 & .12 & -0.03 & .021 & -.04 & 0.03 & .010 & .18 \\
\hline Distinctive-Ordinary & -0.02 & .114 & .08 & 0.02 & .128 & .05 & -0.04 & .005 & .12 & -0.03 & .016 & .02 & 0.02 & .075 & .12 \\
\hline Tight-lipped-Laughing & 0.02 & .115 & .00 & 0.01 & .646 & .01 & -0.01 & .709 & .00 & 0.02 & .097 & .05 & 0.03 & .051 & .07 \\
\hline Tired-Energetic & 0.02 & .139 & .02 & 0.03 & .064 & .04 & -0.02 & .135 & .01 & 0.00 & .817 & .01 & 0.03 & .029 & .08 \\
\hline Tense-Relaxed & 0.02 & .173 & .01 & 0.01 & .399 & .02 & -0.01 & .569 & .00 & 0.02 & .178 & .04 & 0.01 & .315 & .03 \\
\hline Cold-Warm & 0.03 & .070 & .00 & 0.01 & .416 & .01 & -0.01 & .565 & .00 & 0.02 & .147 & .05 & 0.03 & .072 & .06 \\
\hline Masculine-Feminine & 0.02 & .260 & .01 & 0.00 & .850 & .00 & 0.02 & .216 & .01 & 0.05 & .001 & .13 & 0.03 & .013 & .03 \\
\hline Attractiveness & 0.00 & .946 & .00 & 0.03 & .038 & .05 & -0.04 & .005 & .11 & -0.02 & .186 & -.03 & 0.02 & .066 & .09 \\
\hline Non-Duchenne smile & -0.03 & .026 & .02 & -0.01 & .559 & .01 & 0.01 & .518 & .00 & -0.03 & .029 & .08 & -0.03 & .018 & .09 \\
\hline Duchenne smile & 0.02 & .088 & .03 & 0.01 & .455 & .01 & 0.00 & .722 & .01 & 0.03 & .017 & .12 & 0.03 & .017 & .09 \\
\hline No smile & $\mathbf{0 . 0 3}$ & .042 & .01 & 0.00 & .742 & .01 & -0.01 & .460 & .00 & 0.02 & .099 & .07 & 0.03 & .054 & .09 \\
\hline
\end{tabular}

Note. Est. $=$ Parameter estimate for cross-level interaction term when entered as single cross-level interaction. $\mathrm{R}^{2}=$

Pseudo $\mathrm{R}^{2}$-metric calculated from variance accounted in random slopes. Boldface estimates highlight associations that remained statistically significant $(p<.05)$ also in the context of other cross-level interaction terms with personality for same appearance variable. 
Supplementary online material for "Who likes whom? The interaction between perceiver personality and target look"

Tables S01-S18.

Figures S1 and S2. 
Table S1

Means, standard deviations, and correlations of perceiver demographics, personality, and mean liking ratings.

\begin{tabular}{|c|c|c|c|c|c|c|c|c|c|}
\hline Variable & $M$ & $S D$ & 1 & 2 & 3 & 4 & 5 & 6 & 7 \\
\hline 1. Sex & -0.38 & 0.33 & & & & & & & \\
\hline 2. Age & 25.41 & 6.63 & $.12 *$ & & & & & & \\
\hline 3. Liking & 5.41 & 1.07 & $-.14 * *$ & .01 & & & & & \\
\hline 4. Neuroticism & -0.02 & 1.22 & -.05 & -.07 & -.09 & & & & \\
\hline 5. Extraversion & 0.36 & 1.13 & -.09 & .03 & $.16 * *$ & $-.44 * *$ & & & \\
\hline 6. Openness & 1.43 & 0.86 & .01 & .05 & $.13 * *$ & -.05 & $.22 * *$ & & \\
\hline 7. Agreeableness & 1.51 & 0.82 & $-.21 * *$ & -.05 & $.25 * *$ & $-.13 * *$ & -.04 & $.19 * *$ & \\
\hline 8. Consientiousness & 1.15 & 0.97 & $-.13 * *$ & .04 & .07 & $-.50 * *$ & $.24 * *$ & -.04 & $.17 * *$ \\
\hline
\end{tabular}

Note. $n=385$.

$* p<.05 . * * p<.01$. 
Table S2

Means, standard deviations, and correlations of target demographics, appearance, and mean of received liking ratings

\begin{tabular}{|c|c|c|c|c|c|c|c|c|c|c|c|c|c|c|c|c|c|c|c|c|}
\hline Variable & $M$ & $S D$ & $I C C$ & 1 & 2 & 3 & 4 & 5 & 6 & 7 & 8 & 9 & 10 & 11 & 12 & 13 & 14 & 15 & 16 & 17 \\
\hline 1. Sex & -0.01 & 0.50 & & & & & & & & & & & & & & & & & & \\
\hline 2. Age & 34.00 & 4.14 & & .22 & & & & & & & & & & & & & & & & \\
\hline 3. Liking & 5.43 & 0.91 & & -.36 & -.20 & & & & & & & & & & & & & & & \\
\hline 4. Healthy & 5.10 & 0.67 & $.70 / .76$ & -.11 & -.23 & .38 & & & & & & & & & & & & & & \\
\hline 5. Prepared & 4.15 & 0.84 & $.81 / .81$ & -.27 & -.12 & .15 & .39 & & & & & & & & & & & & & \\
\hline 6. Traditional & 4.46 & 0.94 & $.83 / .76$ & .11 & .16 & -.06 & .10 & .21 & & & & & & & & & & & & \\
\hline 7. Stylish & 4.43 & 0.82 & $.79 / .87$ & .09 & .19 & .12 & .33 & .57 & .44 & & & & & & & & & & & \\
\hline 8. Ordinary & 4.70 & 1.08 & $.86 / .79$ & .09 & -.01 & -.05 & .08 & -.01 & .79 & .11 & & & & & & & & & & \\
\hline 9. Neat & 4.86 & 0.77 & $.76 / .86$ & -.04 & .12 & .08 & .28 & .59 & .54 & .86 & .22 & & & & & & & & & \\
\hline 10. Laugh & 3.85 & 1.15 & $.94 / .93$ & -.17 & -.13 & .61 & .38 & .09 & .03 & .05 & .02 & .05 & & & & & & & & \\
\hline 11. Energetic & 3.86 & 0.95 & $.89 / .84$ & -.14 & -.11 & .48 & .61 & .33 & .02 & .23 & -.09 & .22 & .76 & & & & & & & \\
\hline 12. Relaxed & 4.16 & 0.95 & $.89 / .73$ & -.02 & -.16 & .56 & .42 & .00 & -.09 & .01 & -.02 & -.07 & .86 & .67 & & & & & & \\
\hline 13. Warm & 4.41 & 0.91 & $.90 / .81$ & -.17 & -.16 & .66 & .48 & .10 & .07 & .08 & .05 & .07 & .91 & .75 & .88 & & & & & \\
\hline 14. Feminine & 4.04 & 1.23 & $.93 / .92$ & -.86 & -.24 & .45 & .10 & .36 & -.04 & .04 & -.08 & .16 & .25 & .16 & .07 & .23 & & & & \\
\hline 15. Attractiveness & 5.48 & 2.00 & $.89 / .86$ & -.02 & -.19 & .42 & .69 & .41 & .21 & .49 & .18 & .37 & .30 & .37 & .35 & .40 & .15 & & & \\
\hline 16. Non-Duchenne & 0.47 & 0.40 & $.58 / .67$ & .32 & .17 & -.64 & -.36 & -.21 & -.09 & -.11 & -.09 & -.16 & -.88 & -.68 & -.73 & -.85 & -.37 & -.33 & & \\
\hline 17. Duchenne & 0.21 & 0.20 & $.14 / .18$ & -.35 & -.18 & .47 & .19 & .23 & .10 & .07 & .11 & .14 & .52 & .36 & .33 & .49 & .37 & .20 & -.76 & \\
\hline 18. No smile & 0.32 & 0.28 & $.27 / .34$ & -.21 & -.11 & .59 & .38 & .14 & .06 & .11 & .05 & .12 & .88 & .71 & .80 & .86 & .27 & .33 & -.89 & .37 \\
\hline
\end{tabular}

Note. $n=146$. ICC represents interrater reliability for continuous appearance variables (4-15). For smiling variables, Fleiss' kappa for $m$ raters was used. ICC numbers are for first $(\mathrm{n}=102)$ and second set of targets $(\mathrm{n}=44)$ who were rated by different raters $(\mathrm{m}=$ 11 and $m=9$, respectively). Appearance variables 4-14 were rated on a scale from 1 to 7 . Attractiveness was rated by sorting the portraits of each sex to separate piles ranging from 1 (least attractive) to 10 (most attractive) with roughly equal number of portraits in each pile. Correlation coefficients in absolute magnitude $>.16$ are $p<.05$, and $>.21$ are $p<.01$ 
Table S3

Associations between perceiver's personality and general tendency to like from multilevel models

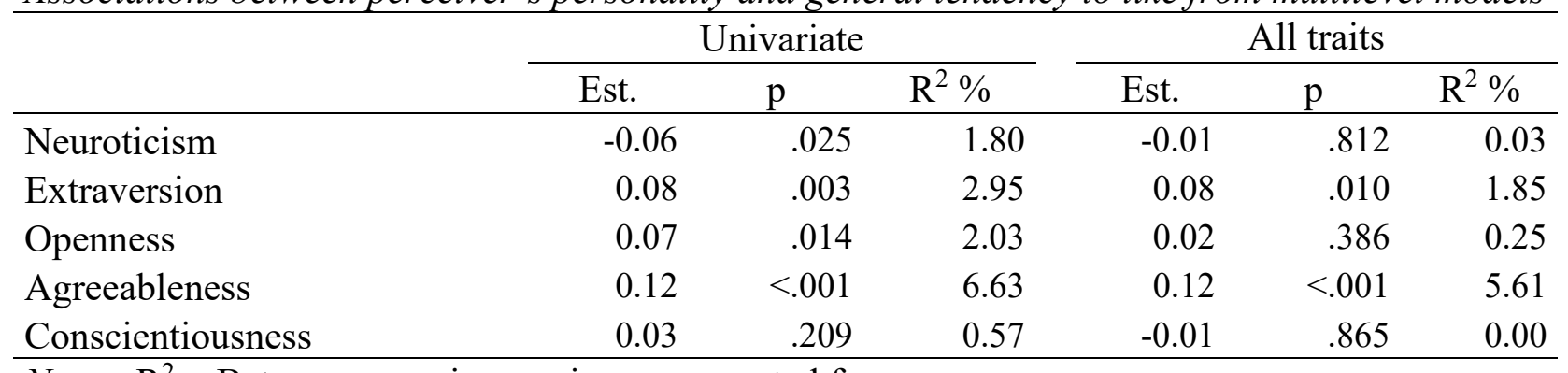

Notes: $\mathrm{R}^{2}=$ Between-perceiver variance accounted for 
Table S4

Parameter estimates from models in which association between perceiver's personality and general tendency to like was estimated

\begin{tabular}{|c|c|c|c|c|c|c|c|c|c|c|c|c|}
\hline Predictors & Est. & $p$ & Est. & $p$ & Est. & $p$ & Est. & $p$ & Est. & $p$ & Est. & $p$ \\
\hline (Intercept) & -0.09 & .069 & -0.08 & .112 & -0.09 & .074 & -0.06 & .217 & -0.09 & .096 & -0.05 & .286 \\
\hline Sex.tar & -0.33 & $<.001$ & -0.33 & $<.001$ & -0.33 & $<.001$ & -0.34 & $<.001$ & -0.33 & $<.001$ & -0.33 & $<.001$ \\
\hline Sex.per & -0.23 & .004 & -0.20 & .012 & -0.23 & .004 & -0.16 & .053 & -0.21 & .009 & -0.13 & .099 \\
\hline Age.tar & -0.01 & .114 & -0.01 & .109 & -0.01 & .118 & -0.01 & .121 & -0.01 & .115 & -0.01 & .115 \\
\hline Age.per & 0.00 & .718 & 0.00 & .672 & 0.00 & .685 & 0.00 & .527 & 0.00 & .655 & 0.00 & .626 \\
\hline Sex.tar * Sex.per & -0.09 & .190 & -0.09 & .193 & -0.09 & .191 & -0.09 & .189 & -0.09 & .191 & -0.09 & .191 \\
\hline $\mathrm{N}$ & -0.06 & .025 & & & & & & & & & -0.01 & .812 \\
\hline $\mathrm{E}$ & & & 0.08 & .003 & & & & & & & 0.08 & .010 \\
\hline $\mathrm{O}$ & & & & & 0.07 & .014 & & & & & 0.02 & .386 \\
\hline A & & & & & & & 0.12 & $<.001$ & & & 0.12 & $<.001$ \\
\hline $\mathrm{C}$ & & & & & & & & & 0.03 & .209 & -0.01 & .865 \\
\hline \multicolumn{13}{|l|}{ Random Effects } \\
\hline Residual & 0.61 & & 0.61 & & 0.61 & & 0.61 & & 0.61 & & 0.61 & \\
\hline Intercept by perceiver & 0.21 & & 0.20 & & 0.21 & & 0.20 & & 0.21 & & 0.19 & \\
\hline Intercept by target & 0.15 & & 0.15 & & 0.15 & & 0.15 & & 0.15 & & 0.15 & \\
\hline
\end{tabular}

Note. .tar and .per refer to target- and perceiver-level variables, respectively. Sex coded -0.5 for females, 0.5 for males. Random effects in variance metric. 


\section{Table S5}

Random intercept variance estimates from different fixed effect models

\begin{tabular}{lccc}
\hline Model & $\begin{array}{c}\text { Perceiver } \\
\left(\mathrm{u}_{\mathrm{j}}\right)\end{array}$ & Target $\left(\mathrm{v}_{\mathrm{k}}\right)$ & $\begin{array}{c}\text { Residual } \\
\left(\mathrm{e}_{\mathrm{ijk}}\right)\end{array}$ \\
\hline Intercepts only & 0.22 & 0.18 & 0.61 \\
Covariates (sex and age) & 0.21 & 0.15 & 0.61 \\
Perceiver personality & 0.19 & 0.15 & 0.61 \\
Target appearance & 0.21 & 0.06 & 0.61 \\
All fixed effects & 0.19 & 0.06 & 0.61 \\
\hline
\end{tabular}


Table S6

Unhealthy vs. Healthy target appearance and interactions with perceiver personality in associations with liking

\begin{tabular}{|c|c|c|c|c|c|c|c|c|c|c|c|c|c|c|}
\hline \multirow[b]{2}{*}{ Predictors } & \multicolumn{2}{|c|}{ Main effects } & \multicolumn{2}{|c|}{ Neuroticism } & \multicolumn{2}{|c|}{ Extraversion } & \multicolumn{2}{|c|}{ Openness } & \multicolumn{2}{|c|}{ Agreeableness } & \multicolumn{2}{|c|}{ Conscient. } & \multicolumn{2}{|c|}{ All traits } \\
\hline & Est. & $p$ & Est. & $p$ & Est. & $p$ & Est. & $p$ & Est. & $p$ & Est. & $p$ & Est. & $p$ \\
\hline (Intercept) & -0.06 & 0.265 & -0.06 & 0.265 & -0.06 & 0.266 & -0.06 & 0.265 & -0.06 & 0.265 & -0.06 & 0.265 & -0.06 & 0.265 \\
\hline Sex.tar & -0.32 & $<0.001$ & -0.32 & $<0.001$ & -0.32 & $<0.001$ & -0.32 & $<0.001$ & -0.32 & $<0.001$ & -0.32 & $<0.001$ & -0.32 & $<0.001$ \\
\hline Sex.per & -0.14 & 0.086 & -0.14 & 0.086 & -0.14 & 0.085 & -0.14 & 0.086 & -0.14 & 0.085 & -0.14 & 0.086 & -0.14 & 0.084 \\
\hline Age.tar & -0.01 & 0.536 & -0.01 & 0.536 & -0.01 & 0.528 & -0.01 & 0.534 & -0.01 & 0.537 & -0.00 & 0.543 & -0.01 & 0.529 \\
\hline Age.per & 0.00 & 0.616 & 0.00 & 0.617 & 0.00 & 0.615 & 0.00 & 0.616 & 0.00 & 0.617 & 0.00 & 0.614 & 0.00 & 0.617 \\
\hline Sex.tar $\times$ Sex.per & -0.10 & 0.156 & -0.09 & 0.159 & -0.10 & 0.123 & -0.10 & 0.155 & -0.09 & 0.158 & -0.10 & 0.144 & -0.11 & 0.100 \\
\hline Healthy.tar & 0.16 & $<0.001$ & 0.16 & $<0.001$ & 0.16 & $<0.001$ & 0.16 & $<0.001$ & 0.16 & $<0.001$ & 0.15 & $<0.001$ & 0.16 & $<0.001$ \\
\hline N.per & -0.01 & 0.797 & -0.01 & 0.800 & -0.01 & 0.797 & -0.01 & 0.797 & -0.01 & 0.796 & -0.01 & 0.796 & -0.01 & 0.814 \\
\hline E.per & 0.08 & 0.011 & 0.08 & 0.011 & 0.08 & 0.010 & 0.08 & 0.011 & 0.08 & 0.011 & 0.08 & 0.011 & 0.08 & 0.010 \\
\hline O.per & 0.02 & 0.373 & 0.02 & 0.372 & 0.02 & 0.371 & 0.02 & 0.376 & 0.02 & 0.372 & 0.02 & 0.374 & 0.02 & 0.375 \\
\hline A.per & 0.12 & $<0.001$ & 0.12 & $<0.001$ & 0.12 & $<0.001$ & 0.12 & $<0.001$ & 0.12 & $<0.001$ & 0.12 & $<0.001$ & 0.12 & $<0.001$ \\
\hline C.per & -0.01 & 0.833 & -0.01 & 0.833 & -0.01 & 0.834 & -0.01 & 0.834 & -0.01 & 0.832 & -0.01 & 0.838 & -0.01 & 0.848 \\
\hline Healthy.tar $\times$ N.per & & & 0.01 & 0.419 & & & & & & & & & 0.05 & 0.001 \\
\hline Healthy.tar $\times$ E.per & & & & & 0.04 & 0.002 & & & & & & & 0.06 & $<0.001$ \\
\hline Healthy.tar $\times$ O.per & & & & & & & -0.02 & 0.171 & & & & & -0.03 & 0.021 \\
\hline Healthy.tar $\times$ A.per & & & & & & & & & -0.01 & 0.406 & & & -0.00 & 0.917 \\
\hline Healthy.tar $\times$ C.per & & & & & & & & & & & 0.02 & 0.074 & 0.03 & 0.017 \\
\hline Random Effects & & & & & & & & & & & & & & \\
\hline Residual & 0.60 & & 0.60 & & 0.60 & & 0.60 & & 0.60 & & 0.60 & & 0.60 & \\
\hline Healthy by perceiver & 0.01 & & 0.01 & & 0.01 & & 0.01 & & 0.01 & & 0.01 & & 0.01 & \\
\hline Intercept by perceiver & 0.19 & & 0.19 & & 0.19 & & 0.19 & & 0.19 & & 0.19 & & 0.19 & \\
\hline Intercept by target & 0.13 & & 0.13 & & 0.13 & & 0.13 & & 0.13 & & 0.13 & & 0.13 & \\
\hline
\end{tabular}

Note. .tar and .per refer to target- and perceirver-level variables, respectively. Sex coded -0.5 for females, 0.5 for males. Random effects in variance metric. 
Table S7

Unprepared vs. Prepared target appearance and interactions with perceiver personality in associations with liking

\begin{tabular}{|c|c|c|c|c|c|c|c|c|c|c|c|c|c|c|}
\hline \multirow[b]{2}{*}{ Predictors } & \multicolumn{2}{|c|}{ Main effects } & \multicolumn{2}{|c|}{ Neuroticism } & \multicolumn{2}{|c|}{ Extraversion } & \multicolumn{2}{|c|}{ Openness } & \multicolumn{2}{|c|}{ Agreeableness } & \multicolumn{2}{|c|}{ Conscient. } & \multicolumn{2}{|c|}{ All traits } \\
\hline & Est. & $p$ & Est. & $p$ & Est. & $p$ & Est. & $p$ & Est. & $p$ & Est. & $p$ & Est. & $p$ \\
\hline (Intercept) & -0.06 & 0.283 & -0.06 & 0.283 & -0.06 & 0.282 & -0.06 & 0.282 & -0.06 & 0.283 & -0.06 & 0.283 & -0.06 & 0.282 \\
\hline Sex.tar & -0.33 & $<0.001$ & -0.33 & $<0.001$ & -0.33 & $<0.001$ & -0.34 & $<0.001$ & -0.33 & $<0.001$ & -0.34 & $<0.001$ & -0.34 & $<0.001$ \\
\hline Sex.per & -0.14 & 0.096 & -0.14 & 0.096 & -0.14 & 0.096 & -0.14 & 0.096 & -0.14 & 0.096 & -0.14 & 0.096 & -0.14 & 0.096 \\
\hline Age.tar & -0.01 & 0.128 & -0.01 & 0.128 & -0.01 & 0.127 & -0.01 & 0.133 & -0.01 & 0.128 & -0.01 & 0.129 & -0.01 & 0.135 \\
\hline Age.per & 0.00 & 0.621 & 0.00 & 0.621 & 0.00 & 0.623 & 0.00 & 0.617 & 0.00 & 0.621 & 0.00 & 0.626 & 0.00 & 0.621 \\
\hline Sex.tar $\times$ Sex.per & -0.10 & 0.146 & -0.10 & 0.145 & -0.10 & 0.135 & -0.10 & 0.138 & -0.10 & 0.157 & -0.11 & 0.113 & -0.11 & 0.098 \\
\hline Prepared.tar & 0.01 & 0.791 & 0.01 & 0.790 & 0.01 & 0.771 & 0.01 & 0.813 & 0.01 & 0.798 & 0.01 & 0.804 & 0.01 & 0.812 \\
\hline N.per & -0.01 & 0.812 & -0.01 & 0.814 & -0.01 & 0.813 & -0.01 & 0.816 & -0.01 & 0.813 & -0.01 & 0.812 & -0.01 & 0.803 \\
\hline E.per & 0.08 & 0.011 & 0.08 & 0.011 & 0.08 & 0.011 & 0.08 & 0.011 & 0.08 & 0.011 & 0.08 & 0.011 & 0.08 & 0.011 \\
\hline O.per & 0.02 & 0.378 & 0.02 & 0.378 & 0.02 & 0.378 & 0.02 & 0.370 & 0.02 & 0.378 & 0.02 & 0.381 & 0.02 & 0.374 \\
\hline A.per & 0.12 & $<0.001$ & 0.12 & $<0.001$ & 0.12 & $<\mathbf{0 . 0 0 1}$ & 0.12 & $<0.001$ & 0.12 & $<0.001$ & 0.12 & $<0.001$ & 0.12 & $<0.001$ \\
\hline C.per & -0.01 & 0.858 & -0.01 & 0.858 & -0.01 & 0.856 & -0.01 & 0.863 & -0.01 & 0.859 & -0.01 & 0.841 & -0.01 & 0.841 \\
\hline Prepared.tar $\times$ N.per & & & -0.00 & 0.765 & & & & & & & & & 0.04 & 0.027 \\
\hline Prepared.tar $\times$ E.per & & & & & 0.03 & 0.038 & & & & & & & 0.04 & 0.005 \\
\hline Prepared.tar $\times$ O.per & & & & & & & -0.03 & 0.025 & & & & & -0.04 & 0.009 \\
\hline Prepared.tar $\times$ A.per & & & & & & & & & -0.01 & 0.608 & & & -0.00 & 0.860 \\
\hline Prepared.tar $\times$ C.per & & & & & & & & & & & 0.04 & 0.003 & 0.05 & 0.002 \\
\hline Random Effects & & & & & & & & & & & & & & \\
\hline Residual & 0.59 & & 0.59 & & 0.59 & & 0.59 & & 0.59 & & 0.59 & & 0.59 & \\
\hline Prepared by perceiver & 0.02 & & 0.02 & & 0.02 & & 0.02 & & 0.02 & & 0.02 & & 0.01 & \\
\hline Intercept by perceiver & 0.19 & & 0.19 & & 0.19 & & 0.19 & & 0.19 & & 0.19 & & 0.19 & \\
\hline Intercept by target & 0.15 & & 0.15 & & 0.15 & & 0.15 & & 0.15 & & 0.15 & & 0.15 & \\
\hline
\end{tabular}

Note. .tar and .per refer to target- and perceiver-level variables, respectively. Sex coded -0.5 for females, 0.5 for males. Random effects in variance metric. 
Table S8

Nontraditional vs. Traditional target appearance and interactions with perceiver personality in associations with liking

\begin{tabular}{|c|c|c|c|c|c|c|c|c|c|c|c|c|c|c|}
\hline \multirow[b]{2}{*}{ Predictors } & \multicolumn{2}{|c|}{ Main effects } & \multicolumn{2}{|c|}{ Neuroticism } & \multicolumn{2}{|c|}{ Extraversion } & \multicolumn{2}{|c|}{ Openness } & \multicolumn{2}{|c|}{ Agreeableness } & \multicolumn{2}{|c|}{ Conscient. } & \multicolumn{2}{|c|}{ All traits } \\
\hline & Est. & $p$ & Est. & $p$ & Est. & $p$ & Est. & $p$ & Est. & $p$ & Est. & $p$ & Est. & $p$ \\
\hline (Intercept) & -0.05 & 0.287 & -0.05 & 0.288 & -0.05 & 0.288 & -0.05 & 0.287 & -0.05 & 0.285 & -0.05 & 0.288 & -0.05 & 0.287 \\
\hline Sex.tar & -0.33 & $<0.001$ & -0.33 & $<0.001$ & -0.33 & $<0.001$ & -0.33 & $<0.001$ & -0.33 & $<0.001$ & -0.33 & $<0.001$ & -0.33 & $<0.001$ \\
\hline Sex.per & -0.13 & 0.101 & -0.13 & 0.101 & -0.13 & 0.101 & -0.13 & 0.101 & -0.13 & 0.099 & -0.13 & 0.101 & -0.13 & 0.101 \\
\hline Age.tar & -0.01 & 0.141 & -0.01 & 0.140 & -0.01 & 0.139 & -0.01 & 0.145 & -0.01 & 0.141 & -0.01 & 0.137 & -0.01 & 0.139 \\
\hline Age.per & 0.00 & 0.626 & 0.00 & 0.625 & 0.00 & 0.627 & 0.00 & 0.625 & 0.00 & 0.626 & 0.00 & 0.624 & 0.00 & 0.622 \\
\hline Sex.tar $\times$ Sex.per & -0.09 & 0.199 & -0.08 & 0.212 & -0.08 & 0.226 & -0.08 & 0.213 & -0.09 & 0.190 & -0.08 & 0.232 & -0.07 & 0.268 \\
\hline Traditional.tar & -0.02 & 0.560 & -0.02 & 0.557 & -0.02 & 0.581 & -0.02 & 0.545 & -0.02 & 0.515 & -0.02 & 0.544 & -0.02 & 0.505 \\
\hline N.per & -0.01 & 0.814 & -0.01 & 0.813 & -0.01 & 0.816 & -0.01 & 0.814 & -0.01 & 0.810 & -0.01 & 0.817 & -0.01 & 0.814 \\
\hline E.per & 0.08 & 0.010 & 0.08 & 0.010 & 0.08 & 0.010 & 0.08 & 0.010 & 0.08 & 0.010 & 0.08 & 0.010 & 0.08 & 0.010 \\
\hline O.per & 0.02 & 0.394 & 0.02 & 0.395 & 0.02 & 0.394 & 0.02 & 0.402 & 0.02 & 0.391 & 0.02 & 0.393 & 0.02 & 0.400 \\
\hline A.per & 0.12 & $<0.001$ & 0.12 & $<0.001$ & 0.12 & $<\mathbf{0 . 0 0 1}$ & 0.12 & $<\mathbf{0 . 0 0 1}$ & 0.12 & $<\mathbf{0 . 0 0 1}$ & 0.12 & $<0.001$ & 0.12 & $<0.001$ \\
\hline C.per & -0.01 & 0.860 & -0.01 & 0.861 & -0.01 & 0.863 & -0.01 & 0.857 & -0.01 & 0.858 & -0.01 & 0.866 & -0.01 & 0.864 \\
\hline Traditional.tar $\times$ N.per & & & -0.03 & 0.033 & & & & & & & & & -0.01 & 0.689 \\
\hline Traditional.tar $\times$ E.per & & & & & 0.03 & 0.048 & & & & & & & 0.03 & 0.074 \\
\hline Traditional.tar $\times$ O.per & & & & & & & -0.05 & 0.001 & & & & & -0.05 & 0.002 \\
\hline Traditional.tar $\times$ A.per & & & & & & & & & -0.03 & 0.024 & & & -0.03 & 0.029 \\
\hline Traditional.tar $\times$ C.per & & & & & & & & & & & 0.04 & 0.004 & 0.03 & 0.035 \\
\hline Random Effects & & & & & & & & & & & & & & \\
\hline Residual & 0.59 & & 0.59 & & 0.59 & & 0.59 & & 0.59 & & 0.59 & & 0.59 & \\
\hline Traditional by perceiver & 0.01 & & 0.01 & & 0.01 & & 0.01 & & 0.01 & & 0.01 & & 0.01 & \\
\hline Intercept by perceiver & 0.19 & & 0.19 & & 0.19 & & 0.19 & & 0.19 & & 0.19 & & 0.19 & \\
\hline Intercept by target & 0.15 & & 0.15 & & 0.15 & & 0.15 & & 0.15 & & 0.15 & & 0.15 & \\
\hline
\end{tabular}

Note. .tar and .per refer to target- and perceiver-level variables, respectively. Sex coded -0.5 for females, 0.5 for males. Random effects in variance metric. 
Table S9

Distinctive vs. Ordinary target appearance and interactions with perceiver personality in associations with liking

\begin{tabular}{|c|c|c|c|c|c|c|c|c|c|c|c|c|c|c|}
\hline \multirow[b]{2}{*}{ Predictors } & \multicolumn{2}{|c|}{ Main effects } & \multicolumn{2}{|c|}{ Neuroticism } & \multicolumn{2}{|c|}{ Extraversion } & \multicolumn{2}{|c|}{ Openness } & \multicolumn{2}{|c|}{ Agreeableness } & \multicolumn{2}{|c|}{ Conscient. } & \multicolumn{2}{|c|}{ All traits } \\
\hline & Est. & $p$ & Est. & $p$ & Est. & $p$ & Est. & Predictors & Est. & $p$ & Est. & $p$ & Est. & $p$ \\
\hline (Intercept) & -0.05 & 0.286 & -0.05 & 0.287 & -0.05 & 0.287 & -0.05 & 0.287 & -0.06 & 0.284 & -0.05 & 0.287 & -0.05 & 0.286 \\
\hline Sex.tar & -0.33 & $<0.001$ & -0.33 & $<0.001$ & -0.33 & $<0.001$ & -0.33 & $<0.001$ & -0.33 & $<0.001$ & -0.33 & $<0.001$ & -0.33 & $<0.001$ \\
\hline Sex.per & -0.13 & 0.100 & -0.13 & 0.100 & -0.13 & 0.100 & -0.13 & 0.100 & -0.13 & 0.099 & -0.13 & 0.100 & -0.13 & 0.100 \\
\hline Age.tar & -0.01 & 0.112 & -0.01 & 0.112 & -0.01 & 0.111 & -0.01 & 0.117 & -0.01 & 0.110 & -0.01 & 0.112 & -0.01 & 0.111 \\
\hline Age.per & 0.00 & 0.627 & 0.00 & 0.624 & 0.00 & 0.627 & 0.00 & 0.627 & 0.00 & 0.627 & 0.00 & 0.624 & 0.00 & 0.623 \\
\hline Sex.tar $\times$ Sex.per & -0.09 & 0.196 & -0.08 & 0.212 & -0.08 & 0.211 & -0.08 & 0.206 & -0.09 & 0.185 & -0.08 & 0.217 & -0.08 & 0.235 \\
\hline Ordinary.tar & -0.02 & 0.632 & -0.02 & 0.629 & -0.02 & 0.647 & -0.02 & 0.618 & -0.02 & 0.593 & -0.02 & 0.624 & -0.02 & 0.583 \\
\hline N.per & -0.01 & 0.807 & -0.01 & 0.803 & -0.01 & 0.807 & -0.01 & 0.806 & -0.01 & 0.803 & -0.01 & 0.808 & -0.01 & 0.803 \\
\hline E.per & 0.08 & 0.010 & 0.08 & 0.010 & 0.08 & 0.010 & 0.08 & 0.010 & 0.08 & 0.010 & 0.08 & 0.010 & 0.08 & 0.010 \\
\hline O.per & 0.02 & 0.390 & 0.02 & 0.391 & 0.02 & 0.390 & 0.02 & 0.401 & 0.02 & 0.388 & 0.02 & 0.390 & 0.02 & 0.398 \\
\hline A.per & 0.12 & $<0.001$ & 0.12 & $<0.001$ & 0.12 & $<0.001$ & 0.12 & $<0.001$ & 0.12 & $<0.001$ & 0.12 & $<0.001$ & 0.12 & $<0.001$ \\
\hline C.per & -0.01 & 0.859 & -0.01 & 0.860 & -0.01 & 0.861 & -0.01 & 0.855 & -0.01 & 0.857 & -0.01 & 0.867 & -0.01 & 0.862 \\
\hline Ordinary.tar $\times$ N.per & & & -0.02 & 0.083 & & & & & & & & & -0.01 & 0.462 \\
\hline Ordinary.tar $\times$ E.per & & & & & 0.02 & 0.155 & & & & & & & 0.02 & 0.242 \\
\hline Ordinary.tar $\times$ O.per & & & & & & & -0.04 & 0.005 & & & & & -0.03 & 0.012 \\
\hline Ordinary.tar $\times$ A.per & & & & & & & & & -0.03 & 0.016 & & & -0.03 & 0.018 \\
\hline Ordinary.tar $\times$ C.per & & & & & & & & & & & 0.03 & 0.046 & 0.02 & 0.163 \\
\hline Random Effects & & & & & & & & & & & & & & \\
\hline Residual & 0.60 & & 0.60 & & 0.60 & & 0.60 & & 0.60 & & 0.60 & & 0.60 & \\
\hline Ordinary by perceiver & 0.01 & & 0.01 & & 0.01 & & 0.01 & & 0.01 & & 0.01 & & 0.01 & \\
\hline Intercept by perceiver & 0.19 & & 0.19 & & 0.19 & & 0.19 & & 0.19 & & 0.19 & & 0.19 & \\
\hline Intercept by target & 0.15 & & 0.15 & & 0.15 & & 0.15 & & 0.15 & & 0.15 & & 0.15 & \\
\hline
\end{tabular}

Note. tar and .per refer to target- and perceiver-level variables, respectively. Sex coded -0.5 for females, 0.5 for males. Random effects in variance metric. 
Table S10

Tight lipped vs. Laughing target appearance and interactions with perceiver personality in associations with liking

\begin{tabular}{|c|c|c|c|c|c|c|c|c|c|c|c|c|c|c|}
\hline \multirow[b]{2}{*}{ Predictors } & \multicolumn{2}{|c|}{ Main effects } & \multicolumn{2}{|c|}{ Neuroticism } & \multicolumn{2}{|c|}{ Extraversion } & \multicolumn{2}{|c|}{ Openness } & \multicolumn{2}{|c|}{ Agreeableness } & \multicolumn{2}{|c|}{ Conscient. } & \multicolumn{2}{|c|}{ All traits } \\
\hline & Est. & $p$ & Est. & $p$ & Est. & $p$ & Est. & $p$ & Est. & $p$ & Est. & $p$ & Est. & $p$ \\
\hline (Intercept) & -0.06 & 0.216 & -0.06 & 0.216 & -0.06 & 0.216 & -0.06 & 0.216 & -0.06 & 0.216 & -0.06 & 0.216 & -0.06 & 0.216 \\
\hline Sex.tar & -0.25 & $<0.001$ & -0.25 & $<0.001$ & -0.25 & $<0.001$ & -0.25 & $<0.001$ & -0.26 & $<0.001$ & -0.26 & $<0.001$ & -0.26 & $<\mathbf{0 . 0 0 1}$ \\
\hline Sex.per & -0.14 & 0.078 & -0.14 & 0.078 & -0.14 & 0.078 & -0.14 & 0.078 & -0.14 & 0.079 & -0.14 & 0.078 & -0.14 & 0.078 \\
\hline Age.tar & -0.01 & 0.249 & -0.01 & 0.251 & -0.01 & 0.248 & -0.01 & 0.249 & -0.01 & 0.252 & -0.01 & 0.248 & -0.01 & 0.252 \\
\hline Age.per & 0.00 & 0.672 & 0.00 & 0.674 & 0.00 & 0.671 & 0.00 & 0.672 & 0.00 & 0.671 & 0.00 & 0.671 & 0.00 & 0.673 \\
\hline Sex.tar $\times$ Sex.per & -0.11 & 0.114 & -0.11 & 0.115 & -0.11 & 0.114 & -0.11 & 0.114 & -0.11 & 0.105 & -0.11 & 0.108 & -0.11 & 0.090 \\
\hline Laugh.tar & 0.26 & $<0.001$ & 0.26 & $<0.001$ & 0.26 & $<0.001$ & 0.26 & $<0.001$ & 0.26 & $<0.001$ & 0.26 & $<0.001$ & 0.27 & $<0.001$ \\
\hline N.per & -0.01 & 0.785 & -0.01 & 0.785 & -0.01 & 0.785 & -0.01 & 0.785 & -0.01 & 0.786 & -0.01 & 0.786 & -0.01 & 0.789 \\
\hline E.per & 0.08 & 0.009 & 0.08 & 0.009 & 0.08 & 0.009 & 0.08 & 0.009 & 0.08 & 0.009 & 0.08 & 0.009 & 0.08 & 0.009 \\
\hline O.per & 0.03 & 0.344 & 0.03 & 0.344 & 0.03 & 0.344 & 0.03 & 0.344 & 0.03 & 0.344 & 0.03 & 0.344 & 0.03 & 0.343 \\
\hline A.per & 0.12 & $<0.001$ & 0.12 & $<0.001$ & 0.12 & $<0.001$ & 0.12 & $<0.001$ & 0.12 & $<0.001$ & 0.12 & $<0.001$ & 0.12 & $<0.001$ \\
\hline C.per & -0.01 & 0.789 & -0.01 & 0.788 & -0.01 & 0.789 & -0.01 & 0.788 & -0.01 & 0.789 & -0.01 & 0.790 & -0.01 & 0.795 \\
\hline Laugh.tar $\times$ N.per & & & 0.03 & 0.079 & & & & & & & & & 0.06 & 0.001 \\
\hline Laugh.tar $\times$ E.per & & & & & 0.01 & 0.582 & & & & & & & 0.03 & 0.096 \\
\hline Laugh.tar $\times$ O.per & & & & & & & -0.00 & 0.885 & & & & & -0.01 & 0.584 \\
\hline Laugh.tar $\times$ A.per & & & & & & & & & 0.02 & 0.179 & & & 0.02 & 0.099 \\
\hline Laugh.tar $\times$ C.per & & & & & & & & & & & 0.02 & 0.107 & 0.04 & 0.012 \\
\hline Random Effects & & & & & & & & & & & & & & \\
\hline Residual & 0.58 & & 0.58 & & 0.58 & & 0.58 & & 0.58 & & 0.58 & & 0.58 & \\
\hline Laugh by perceiver & 0.02 & & 0.02 & & 0.02 & & 0.02 & & 0.02 & & 0.02 & & 0.02 & \\
\hline $\begin{array}{l}\text { Intercept by } \\
\text { perceiver }\end{array}$ & 0.19 & & 0.19 & & 0.19 & & 0.19 & & 0.19 & & 0.19 & & 0.19 & \\
\hline Intercept by target & 0.09 & & 0.09 & & 0.09 & & 0.09 & & 0.09 & & 0.09 & & 0.09 & \\
\hline
\end{tabular}

Note. tar and .per refer to target- and perceiver-level variables, respectively. Sex coded -0.5 for females, 0.5 for males. Random effects in variance metric. 
Table S11

Tired vs. Energetic target appearance and interactions with perceiver personality in associations with liking

\begin{tabular}{|c|c|c|c|c|c|c|c|c|c|c|c|c|c|c|}
\hline \multirow[b]{2}{*}{ Predictors } & \multicolumn{2}{|c|}{ Main effects } & \multicolumn{2}{|c|}{ Neuroticism } & \multicolumn{2}{|c|}{ Extraversion } & \multicolumn{2}{|c|}{ Openness } & \multicolumn{2}{|c|}{ Agreeableness } & \multicolumn{2}{|c|}{ Conscient. } & \multicolumn{2}{|c|}{ All traits } \\
\hline & Est. & $p$ & Est. & $p$ & Est. & $p$ & Est. & $p$ & Est. & $p$ & Est. & $p$ & Est. & $p$ \\
\hline (Intercept) & -0.06 & 0.232 & -0.06 & 0.232 & -0.06 & 0.232 & -0.06 & 0.232 & -0.06 & 0.232 & -0.06 & 0.232 & -0.06 & 0.232 \\
\hline Sex.tar & -0.29 & $<0.001$ & -0.29 & $<\mathbf{0 . 0 0 1}$ & -0.29 & $<0.001$ & -0.29 & $<\mathbf{0 . 0 0 1}$ & -0.29 & $<\mathbf{0 . 0 0 1}$ & -0.29 & $<\mathbf{0 . 0 0 1}$ & -0.30 & $<\mathbf{0 . 0 0 1}$ \\
\hline Sex.per & -0.14 & 0.084 & -0.14 & 0.085 & -0.14 & 0.084 & -0.14 & 0.084 & -0.14 & 0.084 & -0.14 & 0.084 & -0.14 & 0.084 \\
\hline Age.tar & -0.01 & 0.185 & -0.01 & 0.185 & -0.01 & 0.185 & -0.01 & 0.187 & -0.01 & 0.185 & -0.01 & 0.187 & -0.01 & 0.188 \\
\hline Age.per & 0.00 & 0.635 & 0.00 & 0.636 & 0.00 & 0.635 & 0.00 & 0.635 & 0.00 & 0.635 & 0.00 & 0.636 & 0.00 & 0.639 \\
\hline Sex.tar $\times$ Sex.per & -0.10 & 0.119 & -0.10 & 0.127 & -0.11 & 0.109 & -0.11 & 0.115 & -0.10 & 0.119 & -0.11 & 0.113 & -0.11 & 0.102 \\
\hline Energetic.tar & 0.19 & $<0.001$ & 0.19 & $<0.001$ & 0.19 & $<0.001$ & 0.19 & $<0.001$ & 0.19 & $<0.001$ & 0.19 & $<0.001$ & 0.19 & $<0.001$ \\
\hline N.per & -0.01 & 0.786 & -0.01 & 0.784 & -0.01 & 0.786 & -0.01 & 0.787 & -0.01 & 0.786 & -0.01 & 0.786 & -0.01 & 0.785 \\
\hline E.per & 0.08 & 0.010 & 0.08 & 0.010 & 0.08 & 0.010 & 0.08 & 0.010 & 0.08 & 0.010 & 0.08 & 0.010 & 0.08 & 0.010 \\
\hline O.per & 0.02 & 0.361 & 0.02 & 0.361 & 0.02 & 0.360 & 0.02 & 0.361 & 0.02 & 0.361 & 0.02 & 0.363 & 0.02 & 0.360 \\
\hline A.per & 0.12 & $<0.001$ & 0.12 & $<0.001$ & 0.12 & $<0.001$ & 0.12 & $<0.001$ & 0.12 & $<0.001$ & 0.12 & $<0.001$ & 0.12 & $<0.001$ \\
\hline C.per & -0.01 & 0.833 & -0.01 & 0.833 & -0.01 & 0.835 & -0.01 & 0.834 & -0.01 & 0.833 & -0.01 & 0.831 & -0.01 & 0.837 \\
\hline Energetic.tar $\times$ N.per & & & 0.02 & 0.084 & & & & & & & & & 0.07 & $<0.001$ \\
\hline Energetic.tar $\times$ E.per & & & & & 0.02 & 0.069 & & & & & & & 0.05 & 0.001 \\
\hline Energetic.tar $\times$ O.per & & & & & & & -0.02 & 0.168 & & & & & -0.03 & 0.051 \\
\hline Energetic.tar $\times$ A.per & & & & & & & & & -0.00 & 0.938 & & & 0.01 & 0.545 \\
\hline Energetic.tar $\times$ C.per & & & & & & & & & & & 0.03 & 0.054 & 0.05 & 0.003 \\
\hline Random Effects & & & & & & & & & & & & & & \\
\hline Residual & 0.59 & & 0.59 & & 0.59 & & 0.59 & & 0.59 & & 0.59 & & 0.59 & \\
\hline $\begin{array}{l}\text { Energetic by } \\
\text { perceiver }\end{array}$ & 0.02 & & 0.02 & & 0.02 & & 0.02 & & 0.02 & & 0.02 & & 0.01 & \\
\hline $\begin{array}{l}\text { Intercept by } \\
\text { perceiver }\end{array}$ & 0.19 & & 0.19 & & 0.19 & & 0.19 & & 0.19 & & 0.19 & & 0.19 & \\
\hline Intercept by target & 0.12 & & 0.12 & & 0.12 & & 0.12 & & 0.12 & & 0.12 & & 0.12 & \\
\hline
\end{tabular}

\footnotetext{
Note. .tar and .per refer to target- and perceiver-level variables, respectively. Sex coded -0.5 for females, 0.5 for males. Random effects in
} variance metric. 
Table S12

Tense vs. Relaxed target appearance and interactions with perceiver personality in associations with liking

\begin{tabular}{|c|c|c|c|c|c|c|c|c|c|c|c|c|c|c|}
\hline \multirow[b]{2}{*}{ Predictors } & \multicolumn{2}{|c|}{ Main effects } & \multicolumn{2}{|c|}{ Neuroticism } & \multicolumn{2}{|c|}{ Extraversion } & \multicolumn{2}{|c|}{ Openness } & \multicolumn{2}{|c|}{ Agreeableness } & \multicolumn{2}{|c|}{ Conscient. } & \multicolumn{2}{|c|}{ All traits } \\
\hline & Est. & $p$ & Est. & $p$ & Est. & $p$ & Est. & $p$ & Est. & $p$ & Est. & $p$ & Est. & $p$ \\
\hline (Intercept) & -0.06 & 0.240 & -0.06 & 0.240 & -0.06 & 0.240 & -0.06 & 0.239 & -0.06 & 0.240 & -0.06 & 0.239 & -0.06 & 0.241 \\
\hline Sex.tar & -0.34 & $<0.001$ & -0.34 & $<0.001$ & -0.34 & $<\mathbf{0 . 0 0 1}$ & -0.34 & $<\mathbf{0 . 0 0 1}$ & -0.34 & $<0.001$ & -0.34 & $<\mathbf{0 . 0 0 1}$ & -0.34 & $<\mathbf{0 . 0 0 1}$ \\
\hline Sex.per & -0.14 & 0.075 & -0.14 & 0.075 & -0.14 & 0.075 & -0.14 & 0.075 & -0.14 & 0.076 & -0.14 & 0.075 & -0.14 & 0.076 \\
\hline Age.tar & -0.00 & 0.550 & -0.00 & 0.550 & -0.00 & 0.549 & -0.00 & 0.549 & -0.00 & 0.554 & -0.00 & 0.552 & -0.00 & 0.559 \\
\hline Age.per & 0.00 & 0.681 & 0.00 & 0.683 & 0.00 & 0.680 & 0.00 & 0.681 & 0.00 & 0.680 & 0.00 & 0.680 & 0.00 & 0.681 \\
\hline Sex.tar $\times$ Sex.per & -0.10 & 0.152 & -0.09 & 0.157 & -0.10 & 0.151 & -0.10 & 0.151 & -0.10 & 0.152 & -0.10 & 0.150 & -0.09 & 0.162 \\
\hline Relaxed.tar & 0.25 & $<0.001$ & 0.25 & $<0.001$ & 0.25 & $<0.001$ & 0.25 & $<0.001$ & 0.25 & $<0.001$ & 0.25 & $<0.001$ & 0.25 & $<0.001$ \\
\hline N.per & -0.01 & 0.790 & -0.01 & 0.796 & -0.01 & 0.790 & -0.01 & 0.790 & -0.01 & 0.790 & -0.01 & 0.790 & -0.01 & 0.804 \\
\hline E.per & 0.08 & 0.009 & 0.08 & 0.009 & 0.08 & 0.009 & 0.08 & 0.009 & 0.08 & 0.009 & 0.08 & 0.009 & 0.08 & 0.009 \\
\hline O.per & 0.02 & 0.363 & 0.02 & 0.363 & 0.02 & 0.363 & 0.02 & 0.364 & 0.02 & 0.364 & 0.02 & 0.364 & 0.02 & 0.364 \\
\hline A.per & 0.12 & $<0.001$ & 0.12 & $<0.001$ & 0.12 & $<0.001$ & 0.12 & $<0.001$ & 0.12 & $<0.001$ & 0.12 & $<0.001$ & 0.12 & $<0.001$ \\
\hline C.per & -0.01 & 0.788 & -0.01 & 0.789 & -0.01 & 0.789 & -0.01 & 0.788 & -0.01 & 0.789 & -0.01 & 0.791 & -0.01 & 0.799 \\
\hline Relaxed.tar $\times$ N.per & & & 0.02 & 0.142 & & & & & & & & & 0.05 & 0.005 \\
\hline Relaxed.tar $\times$ E.per & & & & & 0.01 & 0.362 & & & & & & & 0.03 & 0.048 \\
\hline Relaxed.tar $\times$ O.per & & & & & & & -0.01 & 0.695 & & & & & -0.01 & 0.365 \\
\hline Relaxed.tar $\times$ A.per & & & & & & & & & 0.01 & 0.373 & & & 0.02 & 0.220 \\
\hline Relaxed.tar $\times$ C.per & & & & & & & & & & & 0.01 & 0.457 & 0.02 & 0.171 \\
\hline Random Effects & & & & & & & & & & & & & & \\
\hline Residual & 0.59 & & 0.59 & & 0.59 & & 0.59 & & 0.59 & & 0.59 & & 0.59 & \\
\hline $\begin{array}{l}\text { Relaxed by } \\
\text { perceiver }\end{array}$ & 0.02 & & 0.02 & & 0.02 & & 0.02 & & 0.02 & & 0.02 & & 0.02 & \\
\hline $\begin{array}{l}\text { Intercept by } \\
\text { perceiver }\end{array}$ & 0.19 & & 0.19 & & 0.19 & & 0.19 & & 0.19 & & 0.19 & & 0.19 & \\
\hline Intercept by target & 0.09 & & 0.09 & & 0.09 & & 0.09 & & 0.09 & & 0.09 & & 0.09 & \\
\hline
\end{tabular}

Note. .tar and .per refer to target- and perceiver-level variables, respectively. Sex coded -0.5 for females, 0.5 for males. Random effects in variance metric. 
Table S13

Cold vs. Warm target appearance and interactions with perceiver personality in associations with liking

\begin{tabular}{|c|c|c|c|c|c|c|c|c|c|c|c|c|c|c|}
\hline \multirow[b]{2}{*}{ Predictors } & \multicolumn{2}{|c|}{ Main effects } & \multicolumn{2}{|c|}{ Neuroticism } & \multicolumn{2}{|c|}{ Extraversion } & \multicolumn{2}{|c|}{ Openness } & \multicolumn{2}{|c|}{ Agreeableness } & \multicolumn{2}{|c|}{ Conscient. } & \multicolumn{2}{|c|}{ All traits } \\
\hline & Est. & $p$ & Est. & $p$ & Est. & $p$ & Est. & $p$ & Est. & $p$ & Est. & $p$ & Est. & $p$ \\
\hline (Intercept) & -0.06 & 0.216 & -0.06 & 0.216 & -0.06 & 0.216 & -0.06 & 0.216 & -0.06 & 0.217 & -0.06 & 0.216 & -0.06 & 0.217 \\
\hline Sex.tar & -0.26 & $<0.001$ & -0.26 & $<0.001$ & -0.26 & $<0.001$ & -0.26 & $<0.001$ & -0.26 & $<0.001$ & -0.26 & $<0.001$ & -0.26 & $<0.001$ \\
\hline Sex.per & -0.15 & 0.074 & -0.15 & 0.074 & -0.15 & 0.074 & -0.15 & 0.074 & -0.15 & 0.074 & -0.15 & 0.074 & -0.15 & 0.074 \\
\hline Age.tar & -0.01 & 0.377 & -0.01 & 0.376 & -0.01 & 0.376 & -0.01 & 0.376 & -0.01 & 0.378 & -0.01 & 0.379 & -0.01 & 0.378 \\
\hline Age.per & 0.00 & 0.630 & 0.00 & 0.632 & 0.00 & 0.630 & 0.00 & 0.630 & 0.00 & 0.630 & 0.00 & 0.629 & 0.00 & 0.631 \\
\hline Sex.tar $\times$ Sex.per & -0.10 & 0.128 & -0.10 & 0.128 & -0.10 & 0.125 & -0.10 & 0.127 & -0.10 & 0.121 & -0.10 & 0.120 & -0.11 & 0.099 \\
\hline Warm.tar & 0.27 & $<0.001$ & 0.27 & $<0.001$ & 0.27 & $<0.001$ & 0.27 & $<0.001$ & 0.27 & $<0.001$ & 0.27 & $<0.001$ & 0.27 & $<0.001$ \\
\hline N.per & -0.01 & 0.800 & -0.01 & 0.803 & -0.01 & 0.800 & -0.01 & 0.800 & -0.01 & 0.800 & -0.01 & 0.800 & -0.01 & 0.810 \\
\hline E.per & 0.08 & 0.010 & 0.08 & 0.010 & 0.08 & 0.010 & 0.08 & 0.010 & 0.08 & 0.010 & 0.08 & 0.010 & 0.08 & 0.010 \\
\hline O.per & 0.03 & 0.352 & 0.03 & 0.351 & 0.03 & 0.351 & 0.03 & 0.352 & 0.03 & 0.352 & 0.03 & 0.353 & 0.03 & 0.351 \\
\hline A.per & 0.12 & $<0.001$ & 0.12 & $<0.001$ & 0.12 & $<0.001$ & 0.12 & $<0.001$ & 0.12 & $<0.001$ & 0.12 & $<0.001$ & 0.12 & $<0.001$ \\
\hline C.per & -0.01 & 0.785 & -0.01 & 0.785 & -0.01 & 0.786 & -0.01 & 0.785 & -0.01 & 0.785 & -0.01 & 0.788 & -0.01 & 0.796 \\
\hline Warm.tar $\times$ N.per & & & 0.03 & 0.052 & & & & & & & & & 0.07 & $<0.001$ \\
\hline Warm.tar $\times$ E.per & & & & & 0.01 & 0.400 & & & & & & & 0.04 & 0.036 \\
\hline Warm.tar $\times$ O.per & & & & & & & -0.01 & 0.691 & & & & & -0.01 & 0.398 \\
\hline Warm.tar $\times$ A.per & & & & & & & & & 0.02 & 0.300 & & & 0.02 & 0.155 \\
\hline Warm.tar $\times$ C.per & & & & & & & & & & & 0.02 & 0.115 & 0.04 & 0.011 \\
\hline Random Effects & & & & & & & & & & & & & & \\
\hline Residual & 0.58 & & 0.58 & & 0.58 & & 0.58 & & 0.58 & & 0.58 & & 0.58 & \\
\hline Warm by perceiver & 0.02 & & 0.02 & & 0.02 & & 0.02 & & 0.02 & & 0.02 & & 0.02 & \\
\hline $\begin{array}{l}\text { Intercept by } \\
\text { perceiver }\end{array}$ & 0.19 & & 0.19 & & 0.19 & & 0.19 & & 0.19 & & 0.19 & & 0.19 & \\
\hline Intercept by target & 0.08 & & 0.08 & & 0.08 & & 0.08 & & 0.08 & & 0.08 & & 0.08 & \\
\hline
\end{tabular}

Note. .tar and .per refer to target- and perceiver-level variables, respectively. Sex coded -0.5 for females, 0.5 for males. Random effects in variance metric. 
Table S14

Masculine vs. Feminine target appearance and interactions with perceiver personality in associations with liking

\begin{tabular}{|c|c|c|c|c|c|c|c|c|c|c|c|c|c|c|}
\hline \multirow[b]{2}{*}{ Predictors } & \multicolumn{2}{|c|}{ Main effects } & \multicolumn{2}{|c|}{ Neuroticism } & \multicolumn{2}{|c|}{ Extraversion } & \multicolumn{2}{|c|}{ Openness } & \multicolumn{2}{|c|}{ Agreeableness } & \multicolumn{2}{|c|}{ Conscient. } & \multicolumn{2}{|c|}{ All traits } \\
\hline & Est. & $p$ & Est. & $p$ & Est. & $p$ & Est. & $p$ & Est. & $p$ & Est. & $p$ & Est. & $p$ \\
\hline (Intercept) & -0.06 & 0.257 & -0.06 & 0.257 & -0.06 & 0.257 & -0.06 & 0.257 & -0.06 & 0.254 & -0.06 & 0.256 & -0.06 & 0.252 \\
\hline Sex.tar & 0.07 & 0.601 & 0.07 & 0.597 & 0.07 & 0.596 & 0.07 & 0.593 & 0.05 & 0.678 & 0.06 & 0.656 & 0.04 & 0.758 \\
\hline Sex.per & -0.14 & 0.091 & -0.14 & 0.091 & -0.14 & 0.091 & -0.14 & 0.091 & -0.14 & 0.090 & -0.14 & 0.091 & -0.14 & 0.088 \\
\hline Age.tar & -0.01 & 0.177 & -0.01 & 0.178 & -0.01 & 0.177 & -0.01 & 0.173 & -0.01 & 0.177 & -0.01 & 0.176 & -0.01 & 0.177 \\
\hline Age.per & 0.00 & 0.640 & 0.00 & 0.639 & 0.00 & 0.640 & 0.00 & 0.640 & 0.00 & 0.641 & 0.00 & 0.643 & 0.00 & 0.642 \\
\hline Sex.tar $\times$ Sex.per & -0.09 & 0.253 & -0.09 & 0.259 & -0.09 & 0.270 & -0.09 & 0.261 & -0.13 & 0.094 & -0.12 & 0.137 & -0.17 & 0.028 \\
\hline Feminine.tar & 0.23 & $<0.001$ & 0.23 & $<0.001$ & 0.23 & $<0.001$ & 0.23 & $<0.001$ & 0.23 & $<0.001$ & 0.23 & $<0.001$ & 0.23 & $<0.001$ \\
\hline N.per & -0.01 & 0.761 & -0.01 & 0.754 & -0.01 & 0.761 & -0.01 & 0.761 & -0.01 & 0.761 & -0.01 & 0.762 & -0.01 & 0.739 \\
\hline E.per & 0.08 & 0.011 & 0.08 & 0.011 & 0.08 & 0.011 & 0.08 & 0.011 & 0.08 & 0.011 & 0.08 & 0.011 & 0.08 & 0.012 \\
\hline O.per & 0.03 & 0.350 & 0.03 & 0.350 & 0.03 & 0.350 & 0.03 & 0.354 & 0.03 & 0.349 & 0.03 & 0.349 & 0.03 & 0.351 \\
\hline A.per & 0.12 & $<0.001$ & 0.12 & $<0.001$ & 0.12 & $<0.001$ & 0.12 & $<0.001$ & 0.12 & $<0.001$ & 0.12 & $<0.001$ & 0.12 & $<0.001$ \\
\hline C.per & -0.01 & 0.827 & -0.01 & 0.826 & -0.01 & 0.827 & -0.01 & 0.827 & -0.01 & 0.826 & -0.01 & 0.816 & -0.01 & 0.807 \\
\hline Feminine.tar $\times$ N.per & & & 0.02 & 0.228 & & & & & & & & & 0.05 & 0.002 \\
\hline Feminine.tar $\times$ E.per & & & & & -0.00 & 0.794 & & & & & & & 0.01 & 0.650 \\
\hline Feminine.tar $\times$ O.per & & & & & & & 0.02 & 0.213 & & & & & 0.01 & 0.410 \\
\hline Feminine.tar $\times$ A.per & & & & & & & & & 0.05 & 0.001 & & & 0.05 & 0.002 \\
\hline Feminine.tar $\times$ C.per & & & & & & & & & & & 0.03 & 0.015 & 0.05 & 0.001 \\
\hline Random Effects & & & & & & & & & & & & & & \\
\hline Residual & 0.58 & & 0.58 & & 0.58 & & 0.58 & & 0.58 & & 0.58 & & 0.58 & \\
\hline $\begin{array}{l}\text { Feminine by } \\
\text { perceiver }\end{array}$ & 0.02 & & 0.02 & & 0.02 & & 0.02 & & 0.02 & & 0.02 & & 0.02 & \\
\hline $\begin{array}{l}\text { Intercept by } \\
\text { perceiver }\end{array}$ & 0.19 & & 0.19 & & 0.19 & & 0.19 & & 0.19 & & 0.19 & & 0.19 & \\
\hline Intercept by target & 0.14 & & 0.14 & & 0.14 & & 0.14 & & 0.14 & & 0.14 & & 0.14 & \\
\hline
\end{tabular}

\footnotetext{
Note. .tar and .per refer to target- and perceiver-level variables, respectively. Sex coded -0.5 for females, 0.5 for males. Random effects in
} variance metric. 
Table S15

Unattractive vs. Attractive target appearance and interactions with perceiver personality in associations with liking

\begin{tabular}{|c|c|c|c|c|c|c|c|c|c|c|c|c|c|c|}
\hline \multirow[b]{2}{*}{ Predictors } & \multicolumn{2}{|c|}{ Main effects } & \multicolumn{2}{|c|}{ Neuroticism } & \multicolumn{2}{|c|}{ Extraversion } & \multicolumn{2}{|c|}{ Openness } & \multicolumn{2}{|c|}{ Agreeableness } & \multicolumn{2}{|c|}{ Conscient. } & \multicolumn{2}{|c|}{ All traits } \\
\hline & Est. & $p$ & Est. & $p$ & Est. & $p$ & Est. & $p$ & Est. & $p$ & Est. & $p$ & Est. & $p$ \\
\hline (Intercept) & -0.06 & 0.236 & -0.06 & 0.236 & -0.06 & 0.236 & -0.06 & 0.235 & -0.06 & 0.235 & -0.06 & 0.236 & -0.06 & 0.236 \\
\hline Sex.tar & -0.34 & $<0.001$ & -0.34 & $<0.001$ & -0.34 & $<0.001$ & -0.34 & $<0.001$ & -0.34 & $<0.001$ & -0.34 & $<\mathbf{0 . 0 0 1}$ & -0.34 & $<0.001$ \\
\hline Sex.per & -0.14 & 0.079 & -0.14 & 0.079 & -0.14 & 0.079 & -0.14 & 0.080 & -0.14 & 0.079 & -0.14 & 0.079 & -0.14 & 0.079 \\
\hline Age.tar & -0.01 & 0.520 & -0.01 & 0.519 & -0.01 & 0.519 & -0.01 & 0.502 & -0.00 & 0.521 & -0.00 & 0.526 & -0.01 & 0.505 \\
\hline Age.per & 0.00 & 0.636 & 0.00 & 0.637 & 0.00 & 0.636 & 0.00 & 0.635 & 0.00 & 0.637 & 0.00 & 0.636 & 0.00 & 0.636 \\
\hline Sex.tar $\times$ Sex.per & -0.09 & 0.184 & -0.09 & 0.184 & -0.09 & 0.178 & -0.09 & 0.189 & -0.09 & 0.184 & -0.09 & 0.184 & -0.09 & 0.173 \\
\hline Attractiveness.tar & 0.18 & $<0.001$ & 0.18 & $<0.001$ & 0.19 & $<\mathbf{0 . 0 0 1}$ & 0.18 & $<0.001$ & 0.18 & $<\mathbf{0 . 0 0 1}$ & 0.18 & $<0.001$ & 0.19 & $<0.001$ \\
\hline N.per & -0.01 & 0.777 & -0.01 & 0.778 & -0.01 & 0.778 & -0.01 & 0.779 & -0.01 & 0.775 & -0.01 & 0.777 & -0.01 & 0.785 \\
\hline E.per & 0.08 & 0.011 & 0.08 & 0.011 & 0.08 & 0.011 & 0.08 & 0.011 & 0.08 & 0.011 & 0.08 & 0.011 & 0.08 & 0.011 \\
\hline O.per & 0.03 & 0.350 & 0.03 & 0.350 & 0.03 & 0.350 & 0.03 & 0.355 & 0.03 & 0.349 & 0.03 & 0.352 & 0.03 & 0.355 \\
\hline A.per & 0.12 & $<0.001$ & 0.12 & $<0.001$ & 0.12 & $<0.001$ & 0.12 & $<0.001$ & 0.12 & $<\mathbf{0 . 0 0 1}$ & 0.12 & $<0.001$ & 0.12 & $<0.001$ \\
\hline C.per & -0.01 & 0.817 & -0.01 & 0.817 & -0.01 & 0.817 & -0.01 & 0.821 & -0.01 & 0.816 & -0.01 & 0.819 & -0.01 & 0.825 \\
\hline Attractiveness.tar $\times$ N.per & & & 0.00 & 0.841 & & & & & & & & & 0.03 & 0.038 \\
\hline Attractiveness.tar $\times$ E.per & & & & & 0.02 & 0.049 & & & & & & & 0.04 & 0.003 \\
\hline Attractiveness.tar $\times$ O.per & & & & & & & -0.04 & 0.006 & & & & & -0.04 & 0.002 \\
\hline Attractiveness.tar $\times$ A.per & & & & & & & & & -0.02 & 0.127 & & & -0.01 & 0.451 \\
\hline Attractiveness.tar $\times$ C.per & & & & & & & & & & & 0.02 & 0.078 & 0.03 & 0.051 \\
\hline Random Effects & & & & & & & & & & & & & & \\
\hline Residual & 0.60 & & 0.60 & & 0.59 & & 0.59 & & 0.59 & & 0.60 & & 0.59 & \\
\hline $\begin{array}{l}\text { Attractiveness by } \\
\text { perceiver }\end{array}$ & 0.01 & & 0.01 & & 0.01 & & 0.01 & & 0.01 & & 0.01 & & 0.01 & \\
\hline Intercept by perceiver & 0.19 & & 0.19 & & 0.19 & & 0.19 & & 0.19 & & 0.19 & & 0.19 & \\
\hline Intercept by target & 0.12 & & 0.12 & & 0.12 & & 0.12 & & 0.12 & & 0.12 & & 0.12 & \\
\hline
\end{tabular}

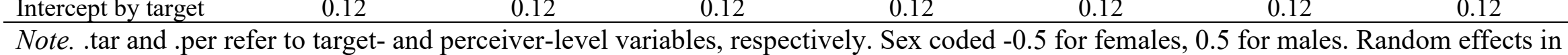
variance metric. 
Table S16

Non-Duchenne target smiles and interactions with perceiver personality in associations with liking

\begin{tabular}{|c|c|c|c|c|c|c|c|c|c|c|c|c|c|c|}
\hline \multirow[b]{2}{*}{ Predictors } & \multicolumn{2}{|c|}{ Main effects } & \multicolumn{2}{|c|}{ Neuroticism } & \multicolumn{2}{|c|}{ Extraversion } & \multicolumn{2}{|c|}{ Openness } & \multicolumn{2}{|c|}{ Agreeableness } & \multicolumn{2}{|c|}{ Conscient. } & \multicolumn{2}{|c|}{ All traits } \\
\hline & Est. & $p$ & Est. & $p$ & Est. & $p$ & Est. & $p$ & Est. & $p$ & Est. & $p$ & Est. & $p$ \\
\hline (Intercept) & -0.06 & 0.232 & -0.06 & 0.232 & -0.06 & 0.232 & -0.06 & 0.232 & -0.06 & 0.233 & -0.06 & 0.232 & -0.06 & 0.232 \\
\hline Sex.tar & -0.18 & 0.005 & -0.18 & 0.005 & -0.18 & 0.005 & -0.18 & 0.005 & -0.18 & 0.004 & -0.18 & 0.004 & -0.19 & 0.004 \\
\hline Sex.per & -0.14 & 0.077 & -0.14 & 0.077 & -0.14 & 0.077 & -0.14 & 0.077 & -0.14 & 0.077 & -0.14 & 0.076 & -0.14 & 0.076 \\
\hline Age.tar & -0.01 & 0.282 & -0.01 & 0.283 & -0.01 & 0.282 & -0.01 & 0.284 & -0.01 & 0.286 & -0.01 & 0.283 & -0.01 & 0.289 \\
\hline Age.per & 0.00 & 0.670 & 0.00 & 0.673 & 0.00 & 0.670 & 0.00 & 0.671 & 0.00 & 0.669 & 0.00 & 0.669 & 0.00 & 0.671 \\
\hline Sex.tar $\times$ Sex.per & -0.11 & 0.108 & -0.11 & 0.104 & -0.11 & 0.107 & -0.11 & 0.107 & -0.12 & 0.088 & -0.11 & 0.095 & -0.13 & 0.051 \\
\hline NON-DUCH..tar & -0.26 & $<0.001$ & -0.26 & $<0.001$ & -0.26 & $<0.001$ & -0.26 & $<0.001$ & -0.26 & $<0.001$ & -0.26 & $<\mathbf{0 . 0 0 1}$ & -0.27 & $<0.001$ \\
\hline N.per & -0.01 & 0.773 & -0.01 & 0.774 & -0.01 & 0.773 & -0.01 & 0.773 & -0.01 & 0.774 & -0.01 & 0.773 & -0.01 & 0.780 \\
\hline E.per & 0.08 & 0.010 & 0.08 & 0.010 & 0.08 & 0.010 & 0.08 & 0.010 & 0.08 & 0.010 & 0.08 & 0.010 & 0.08 & 0.010 \\
\hline O.per & 0.03 & 0.327 & 0.03 & 0.326 & 0.03 & 0.326 & 0.03 & 0.327 & 0.03 & 0.328 & 0.03 & 0.326 & 0.03 & 0.326 \\
\hline A.per & 0.12 & $<0.001$ & 0.12 & $<0.001$ & 0.12 & $<0.001$ & 0.12 & $<0.001$ & 0.12 & $<0.001$ & 0.12 & $<\mathbf{0 . 0 0 1}$ & 0.12 & $<0.001$ \\
\hline C.per & -0.01 & 0.790 & -0.01 & 0.790 & -0.01 & 0.792 & -0.01 & 0.790 & -0.01 & 0.792 & -0.01 & 0.794 & -0.01 & 0.801 \\
\hline $\begin{array}{l}\text { NON-DUCH..tar } \times \\
\text { N.per }\end{array}$ & & & -0.03 & 0.018 & & & & & & & & & -0.08 & $<0.001$ \\
\hline $\begin{array}{l}\text { NON-DUCH..tar } \times \\
\text { E.per }\end{array}$ & & & & & -0.01 & 0.550 & & & & & & & -0.03 & 0.024 \\
\hline $\begin{array}{l}\text { NON-DUCH..tar } \times \\
\text { O.per }\end{array}$ & & & & & & & 0.01 & 0.631 & & & & & 0.02 & 0.275 \\
\hline $\begin{array}{l}\text { NON-DUCH..tar } \times \\
\text { A.per }\end{array}$ & & & & & & & & & -0.03 & 0.060 & & & -0.03 & 0.019 \\
\hline $\begin{array}{l}\text { NON-DUCH..tar } \times \\
\text { C.per }\end{array}$ & & & & & & & & & & & -0.03 & 0.036 & -0.05 & 0.001 \\
\hline Random Effects & & & & & & & & & & & & & & \\
\hline Residual & 0.59 & & 0.59 & & 0.59 & & 0.59 & & 0.59 & & 0.59 & & 0.59 & \\
\hline Non-DU by perceiver & 0.02 & & 0.02 & & 0.02 & & 0.02 & & 0.02 & & 0.02 & & 0.01 & \\
\hline Intercept by perceiver & 0.19 & & 0.19 & & 0.19 & & 0.19 & & 0.19 & & 0.19 & & 0.19 & \\
\hline Intercept by target & 0.09 & & 0.09 & & 0.09 & & 0.09 & & 0.09 & & 0.09 & & 0.09 & \\
\hline
\end{tabular}

Note. .tar and .per refer to target- and perceiver-level variables, respectively. Sex coded -0.5 for females, 0.5 for males. Random effects in variance metric. 
Table S17

Duchenne target smiles and interactions with perceiver personality in associations with liking

\begin{tabular}{|c|c|c|c|c|c|c|c|c|c|c|c|c|c|c|}
\hline \multirow[b]{2}{*}{ Predictors } & \multicolumn{2}{|c|}{ Main effects } & \multicolumn{2}{|c|}{ Neuroticism } & \multicolumn{2}{|c|}{ Extraversion } & \multicolumn{2}{|c|}{ Openness } & \multicolumn{2}{|c|}{ Agreeableness } & \multicolumn{2}{|c|}{ Conscient. } & \multicolumn{2}{|c|}{ All traits } \\
\hline & Est. & $p$ & Est. & $p$ & Est. & $p$ & Est. & $p$ & Est. & $p$ & Est. & $p$ & Est. & $p$ \\
\hline (Intercept) & -0.05 & 0.279 & -0.05 & 0.280 & -0.05 & 0.279 & -0.05 & 0.279 & -0.05 & 0.279 & -0.05 & 0.278 & -0.05 & 0.278 \\
\hline Sex.tar & -0.23 & 0.002 & -0.23 & 0.002 & -0.23 & 0.002 & -0.23 & 0.002 & -0.23 & 0.002 & -0.23 & 0.002 & -0.23 & 0.002 \\
\hline Sex.per & -0.14 & 0.093 & -0.14 & 0.093 & -0.14 & 0.093 & -0.14 & 0.093 & -0.14 & 0.093 & -0.14 & 0.092 & -0.14 & 0.092 \\
\hline Age.tar & -0.01 & 0.255 & -0.01 & 0.254 & -0.01 & 0.255 & -0.01 & 0.256 & -0.01 & 0.258 & -0.01 & 0.256 & -0.01 & 0.259 \\
\hline Age.per & 0.00 & 0.635 & 0.00 & 0.636 & 0.00 & 0.635 & 0.00 & 0.635 & 0.00 & 0.635 & 0.00 & 0.634 & 0.00 & 0.636 \\
\hline Sex.tar $\times$ Sex.per & -0.11 & 0.122 & -0.10 & 0.125 & -0.11 & 0.117 & -0.11 & 0.120 & -0.11 & 0.095 & -0.11 & 0.102 & -0.13 & 0.057 \\
\hline DUCHENNE.tar & 0.17 & $<0.001$ & 0.17 & $<0.001$ & 0.17 & $<0.001$ & 0.17 & $<0.001$ & 0.17 & $<0.001$ & 0.17 & $<\mathbf{0 . 0 0 1}$ & 0.17 & $<0.001$ \\
\hline N.per & -0.01 & 0.800 & -0.01 & 0.803 & -0.01 & 0.800 & -0.01 & 0.800 & -0.01 & 0.802 & -0.01 & 0.799 & -0.01 & 0.808 \\
\hline E.per & 0.08 & 0.010 & 0.08 & 0.010 & 0.08 & 0.010 & 0.08 & 0.010 & 0.08 & 0.010 & 0.08 & 0.010 & 0.08 & 0.010 \\
\hline O.per & 0.03 & 0.353 & 0.03 & 0.352 & 0.03 & 0.353 & 0.03 & 0.353 & 0.03 & 0.354 & 0.03 & 0.352 & 0.03 & 0.353 \\
\hline A.per & 0.12 & $<0.001$ & 0.12 & $<0.001$ & 0.12 & $<\mathbf{0 . 0 0 1}$ & 0.12 & $<0.001$ & 0.12 & $<0.001$ & 0.12 & $<\mathbf{0 . 0 0 1}$ & 0.12 & $<0.001$ \\
\hline C.per & -0.01 & 0.840 & -0.01 & 0.841 & -0.01 & 0.840 & -0.01 & 0.840 & -0.01 & 0.841 & -0.01 & 0.843 & -0.01 & 0.847 \\
\hline $\begin{array}{l}\text { DUCHENNE.tar } \times \\
\text { N.per }\end{array}$ & & & 0.02 & 0.071 & & & & & & & & & 0.07 & $<0.001$ \\
\hline $\begin{array}{l}\text { DUCHENNE.tar } \times \\
\text { E.per }\end{array}$ & & & & & 0.01 & 0.447 & & & & & & & 0.03 & 0.031 \\
\hline $\begin{array}{l}\text { DUCHENNE.tar } \times \\
\text { O.per }\end{array}$ & & & & & & & -0.00 & 0.763 & & & & & -0.01 & 0.312 \\
\hline $\begin{array}{l}\text { DUCHENNE.tar } \times \\
\text { A.per }\end{array}$ & & & & & & & & & 0.03 & 0.036 & & & 0.03 & 0.013 \\
\hline $\begin{array}{l}\text { DUCHENNE.tar } \times \\
\text { C.per }\end{array}$ & & & & & & & & & & & 0.03 & 0.029 & 0.04 & 0.002 \\
\hline Random Effects & & & & & & & & & & & & & & \\
\hline Residual & 0.59 & & 0.59 & & 0.59 & & 0.59 & & 0.59 & & 0.59 & & 0.59 & \\
\hline DUCH by perceiver & 0.01 & & 0.01 & & 0.01 & & 0.01 & & 0.01 & & 0.01 & & 0.01 & \\
\hline Intercept by perceiver & 0.19 & & 0.19 & & 0.19 & & 0.19 & & 0.19 & & 0.19 & & 0.19 & \\
\hline Intercept by target & 0.13 & & 0.13 & & 0.13 & & 0.13 & & 0.13 & & 0.13 & & 0.13 & \\
\hline
\end{tabular}

Note. .tar and .per refer to target- and perceiver-level variables, respectively. Sex coded -0.5 for females, 0.5 for males. Random effects in variance metric. 
Table S18

Target non-smiling expressions and interactions with perceiver personality in associations with liking

\begin{tabular}{|c|c|c|c|c|c|c|c|c|c|c|c|c|c|c|}
\hline \multirow[b]{2}{*}{ Predictors } & \multicolumn{2}{|c|}{ Main effects } & \multicolumn{2}{|c|}{ Neuroticism } & \multicolumn{2}{|c|}{ Extraversion } & \multicolumn{2}{|c|}{ Openness } & \multicolumn{2}{|c|}{ Agreeableness } & \multicolumn{2}{|c|}{ Conscient. } & \multicolumn{2}{|c|}{ All traits } \\
\hline & Est. & $p$ & Est. & $p$ & Est. & $p$ & Est. & $p$ & Est. & $p$ & Est. & $p$ & Est. & $p$ \\
\hline (Intercept) & -0.06 & 0.228 & -0.06 & 0.227 & -0.06 & 0.228 & -0.06 & 0.228 & -0.06 & 0.229 & -0.06 & 0.228 & -0.06 & 0.229 \\
\hline Sex.tar & -0.24 & $<0.001$ & -0.24 & $<0.001$ & -0.24 & $<0.001$ & -0.24 & $<0.001$ & -0.24 & $<0.001$ & -0.24 & $<0.001$ & -0.25 & $<0.001$ \\
\hline Sex.per & -0.14 & 0.075 & -0.14 & 0.075 & -0.14 & 0.075 & -0.14 & 0.075 & -0.14 & 0.076 & -0.14 & 0.075 & -0.14 & 0.076 \\
\hline Age.tar & -0.01 & 0.154 & -0.01 & 0.155 & -0.01 & 0.153 & -0.01 & 0.154 & -0.01 & 0.155 & -0.01 & 0.154 & -0.01 & 0.158 \\
\hline Age.per & 0.00 & 0.675 & 0.00 & 0.678 & 0.00 & 0.674 & 0.00 & 0.675 & 0.00 & 0.673 & 0.00 & 0.673 & 0.00 & 0.677 \\
\hline Sex.tar $\times$ Sex.per & -0.09 & 0.161 & -0.10 & 0.153 & -0.09 & 0.161 & -0.09 & 0.160 & -0.10 & 0.145 & -0.10 & 0.151 & -0.11 & 0.106 \\
\hline NON-SMILE.tar & 0.24 & $<0.001$ & 0.24 & $<0.001$ & 0.24 & $<0.001$ & 0.24 & $<0.001$ & 0.24 & $<0.001$ & 0.24 & $<0.001$ & 0.24 & $<0.001$ \\
\hline N.per & -0.01 & 0.766 & -0.01 & 0.766 & -0.01 & 0.766 & -0.01 & 0.766 & -0.01 & 0.768 & -0.01 & 0.768 & -0.01 & 0.772 \\
\hline E.per & 0.08 & 0.011 & 0.08 & 0.011 & 0.08 & 0.011 & 0.08 & 0.011 & 0.08 & 0.010 & 0.08 & 0.010 & 0.08 & 0.010 \\
\hline O.per & 0.03 & 0.344 & 0.03 & 0.343 & 0.03 & 0.344 & 0.03 & 0.344 & 0.03 & 0.345 & 0.03 & 0.344 & 0.03 & 0.343 \\
\hline A.per & 0.12 & $<0.001$ & 0.12 & $<0.001$ & 0.12 & $<0.001$ & 0.12 & $<0.001$ & 0.12 & $<0.001$ & 0.12 & $<0.001$ & 0.12 & $<0.001$ \\
\hline C.per & -0.01 & 0.789 & -0.01 & 0.787 & -0.01 & 0.790 & -0.01 & 0.788 & -0.01 & 0.790 & -0.01 & 0.791 & -0.01 & 0.799 \\
\hline $\begin{array}{l}\text { NON-SMILE.tar } \times \\
\text { N.per }\end{array}$ & & & 0.03 & $\mathbf{0 . 0 3 0}$ & & & & & & & & & 0.07 & $<0.001$ \\
\hline $\begin{array}{l}\text { NON-SMILE.tar } \times \\
\text { E.per }\end{array}$ & & & & & 0.00 & 0.730 & & & & & & & 0.03 & 0.069 \\
\hline $\begin{array}{l}\text { NON-SMILE.tar } \times \\
\text { O.per }\end{array}$ & & & & & & & -0.01 & 0.582 & & & & & -0.01 & 0.344 \\
\hline $\begin{array}{l}\text { NON-SMILE.tar } \times \\
\text { A.per }\end{array}$ & & & & & & & & & 0.02 & 0.155 & & & 0.03 & 0.060 \\
\hline $\begin{array}{l}\text { NON-SMILE.tar } \times \\
\text { C.per }\end{array}$ & & & & & & & & & & & 0.02 & 0.090 & 0.04 & 0.004 \\
\hline Random Effects & & & & & & & & & & & & & & \\
\hline Residual & 0.59 & & 0.59 & & 0.59 & & 0.59 & & 0.59 & & 0.59 & & 0.59 & \\
\hline $\begin{array}{l}\text { NON-SMILE by } \\
\text { perceiver }\end{array}$ & 0.01 & & 0.01 & & 0.01 & & 0.01 & & 0.01 & & 0.01 & & 0.01 & \\
\hline Intercept by perceiver & 0.19 & & 0.19 & & 0.19 & & 0.19 & & 0.19 & & 0.19 & & 0.19 & \\
\hline Intercept by target & 0.10 & & 0.10 & & 0.10 & & 0.10 & & 0.10 & & 0.10 & & 0.10 & \\
\hline
\end{tabular}

Note. .tar and .per refer to target- and perceiver-level variables, respectively. Sex coded -0.5 for females, 0.5 for males. Random effects in variance metric. 
Figure S1. Example portrait (female).

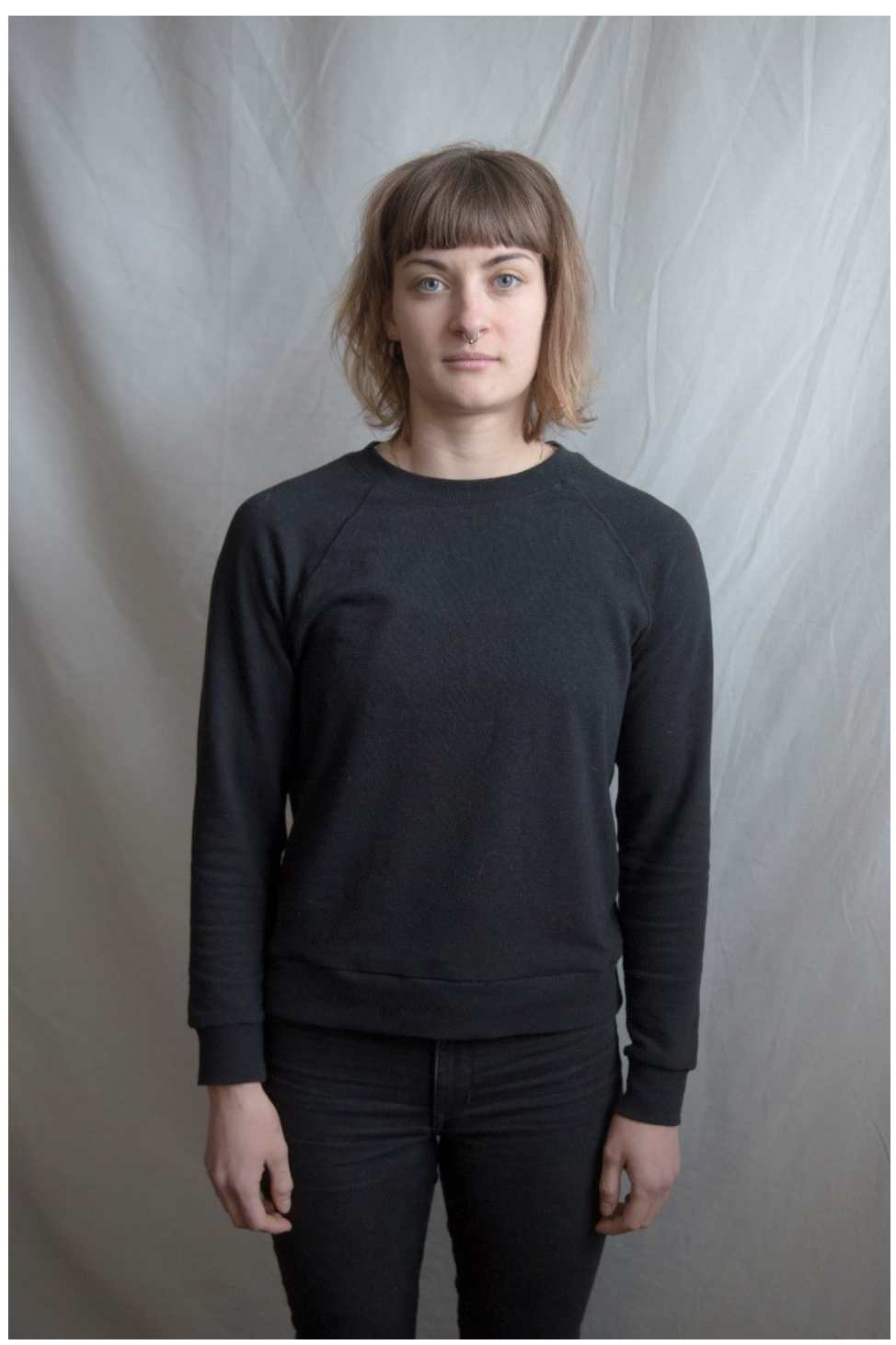



